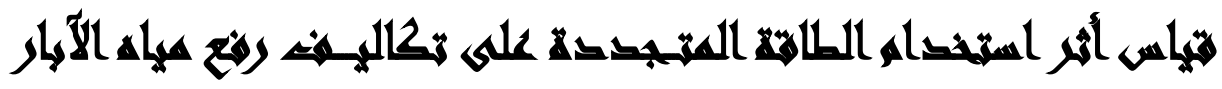

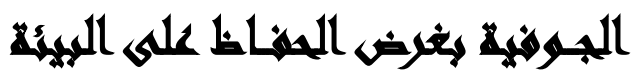

$[1 \cdot]$

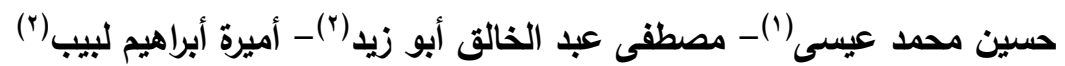
() كلية التجارة، جامعة عين شمس r) وزارة الموارد المائية والري الري

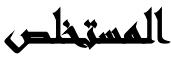

تهدف الدراسة إلى قياس أثز استخدام الطاقة المتجددة على تكاليف رفع مياه الابار

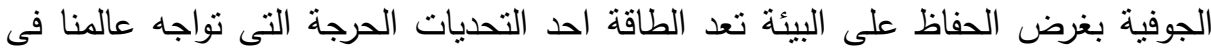

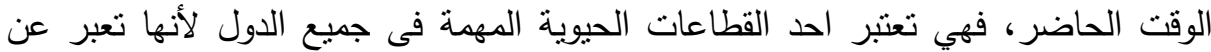
العمليات التتموية، غير ان التطور والنية النمو الاقتصادي الذي شهده العالم في العقود القليلة

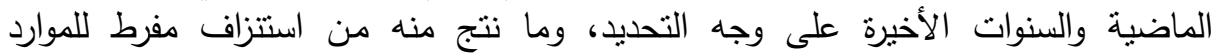

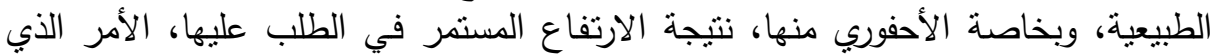
بات يهدد أمن الطاقة العالمي، غير أن ذلك لا يتوقف فقط على إلى إكانية نفاد مصادر الطاقة، الطان.

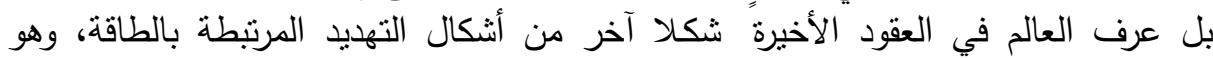

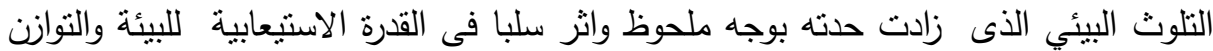

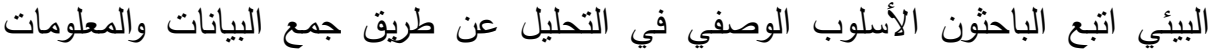

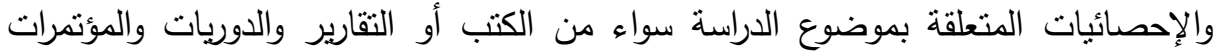

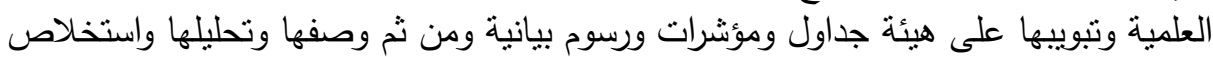

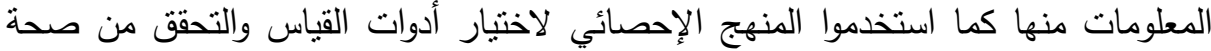
الفروض باستخدام الأساليب الإحصائية واسنتباط النتائج وتفسيرها.

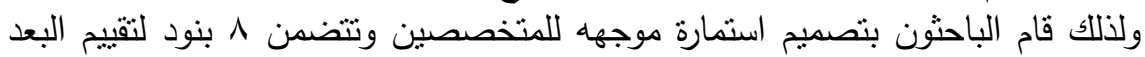

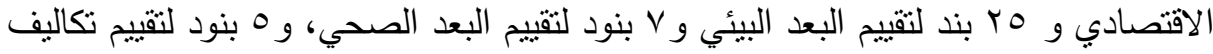

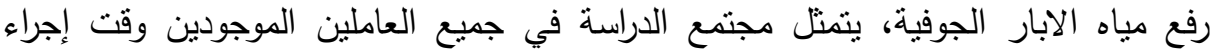

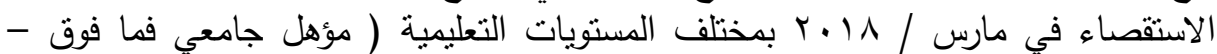

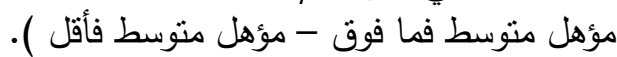
مكان إجراء الدراسة: محطة الطاقة الثمسية بوادي النطرون التابعة لوزائة لوزارة الموارد المائية والري

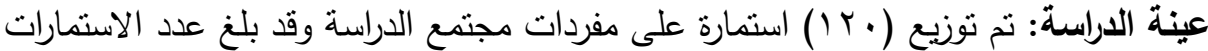

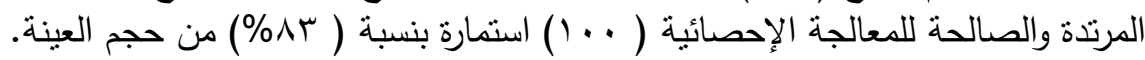

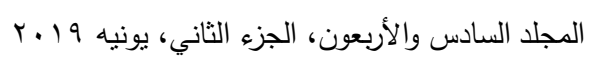


من خلال تفسيرها. وكاتت من أهم النتائج التي توصلت إليها هذه الداراسة:

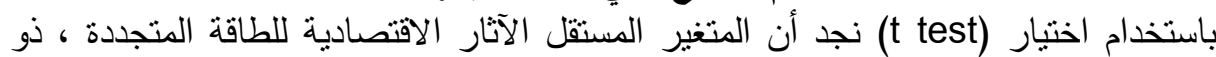

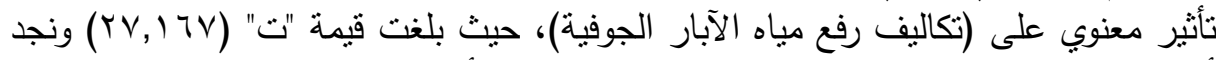

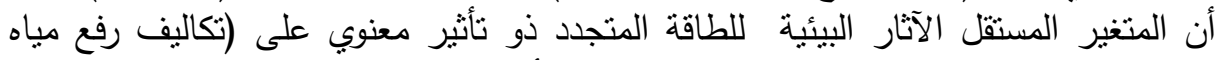

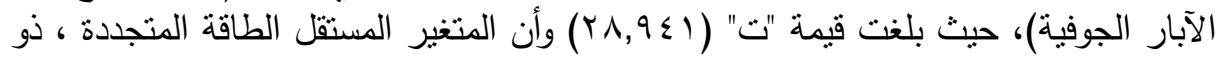

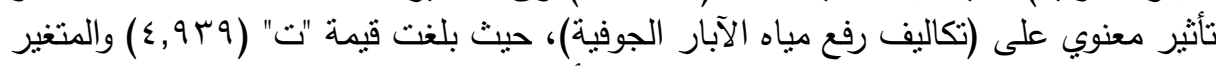

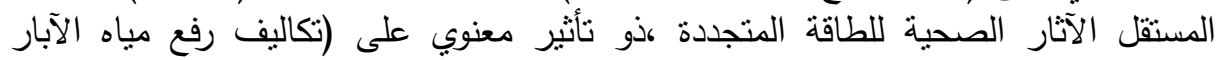

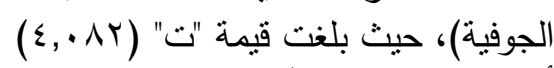

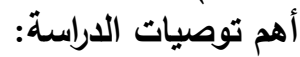
في ضوء نتائج الدراسة توصنى الباءة الباحثة بالآتي:

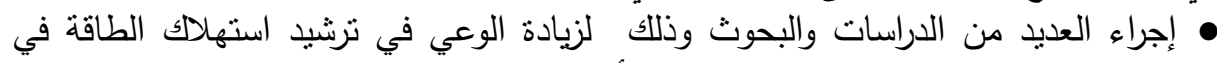

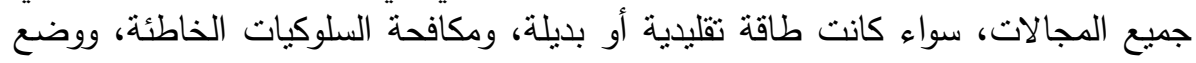

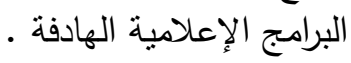
• تتظيم العديد من الندوات والمؤتمرات وورش العمل وذللك لتطوير ودعم المؤسسات والهيئات

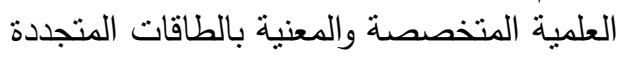

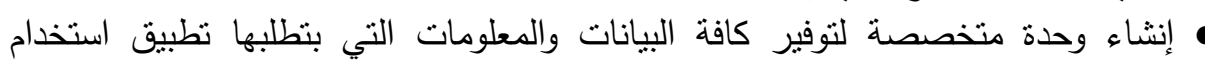
الطاقة المتجدة في توليد الكهرباء في جميع المجالات وخاصة في عملية رفع مياه الآبات لنيار

الجوفية.

\section{xasiadl}

يحظى موضوع الطاقة بالاهتمام البالغ منذ العقود الماضية لما يحمله من أهمية

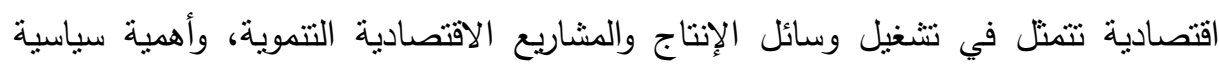

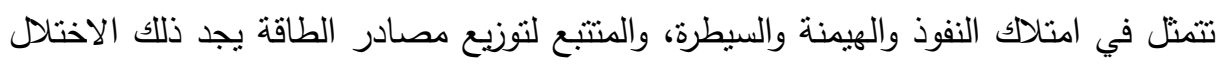

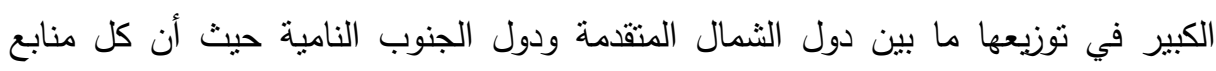

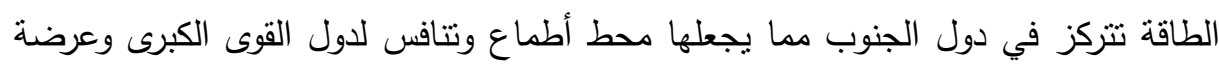
لتعميق التبعية والاستغلال ، ومصر ضمن هذه دول المنظومة حالها كحال دول الجنوب فباعتبار

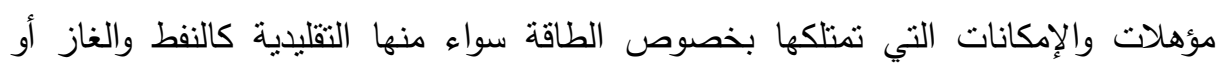

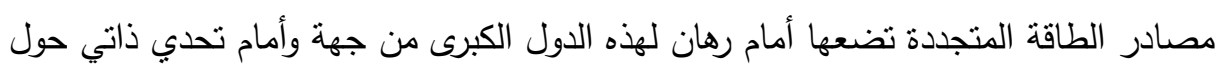
كيفية الاستغلال الناجع لهذه الثروة، وقد تصاعد الحديث في الآونة الأخيرة عن أمان الطاقة

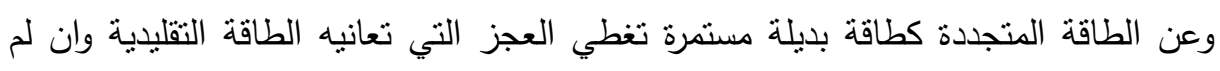
266

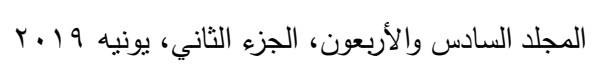


تلغه باعنبارها طاقة بديلة نابعة من مصادر الطبيعة الدائمة والمستمرة والمتجددة كالطاقة الثمسية وطاقة الرياح والمياه والكتلة الحية ، وغيرها والملاحظ على هذه هذه المصادر أنها تتمركز

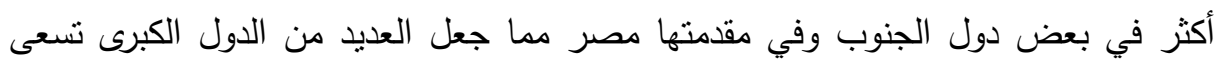
للاستثمار والثراكة معها في مصادر هذه الطاقة خاصة لما تحمله من تكاليف باهظة لاستغلالها والاستثمار فيها والتي تعجز الدول الدصدر منفردة على القيام بها .(محمد طالبي،

ولقد أخذت مصر المبادرة لخوض التجربة في الاستثمار في الطاقة المتجددة كطاقة بديلة عن طاقة الوقود الأحفوري الناضبة من أجل تحقيق التتمية المستدامة وحفظ حق الأجيال

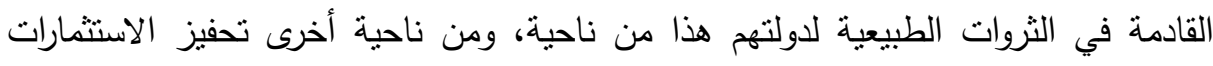

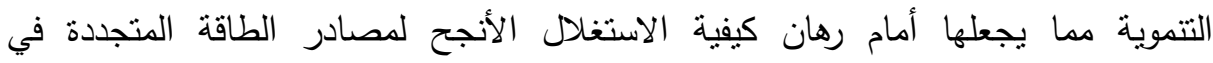
مصر (محمد مصطفى الخياط، ع ( ب ) ). تعتبر شمس مصر مصدراً للطاقة المتجددة لا نتضب واحدي أهم وأعظم آليات التتمية النظيفة، وتقدر كمية الطاقة الثمسية المتدفقة إلى سطح أرض مصر بمقدار ...7 مليون

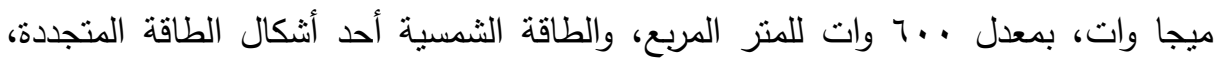
والتي يندرج تحتها (طاقة الرياح - طاقة المساقط المائية - طاقة الوقود الحيوي- طاقة باطن الأرض الحرارية...)، ومصر تَعتندُ على مصدر مائي رئيسِي هو مياه نهر النيلِ بحصة ثابتة

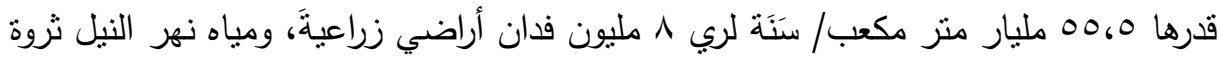

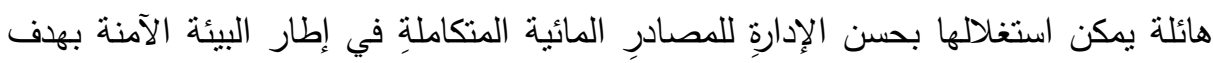
تأمين الموارد المائية للأجيال الحالية والمستقبلية من حيث الكم والنئ النوع مع الاستخدام الأمتل لهذه الموارد من المنظور الاقتصادي والاجتماعي والبيئي للوفاء بالاحتياجات المائية لكافة القطاعات المستخدمة للمياه ( الزراعة - الصناعة - الثرب - الملاحة...) من حيث الثروطِ والمعايير البيئية في إطار الأنظمة البيئية المتكاملة ( المياه سطحية -المياه الجوفية- إعادة

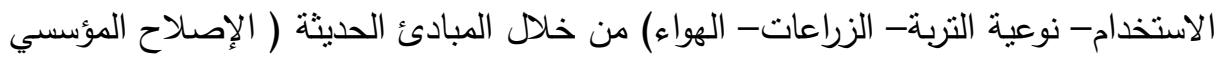


ووضع التشريعات اللازمة للإدارة المتكاملة - التتمية البشرية -مشاركة المنتقعين ونقل

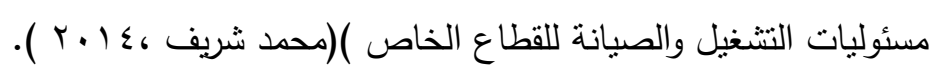

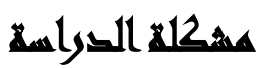

تتاولت الكثير من الدراسات مثل دراسة رشاد محمد محمد عبده، عام ^ +. بام بعنوان

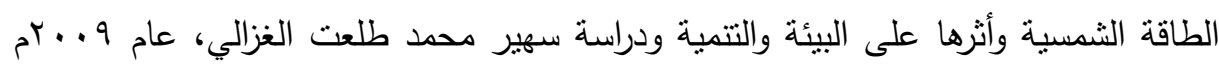

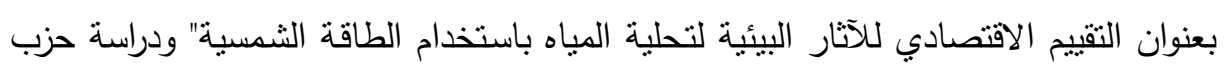

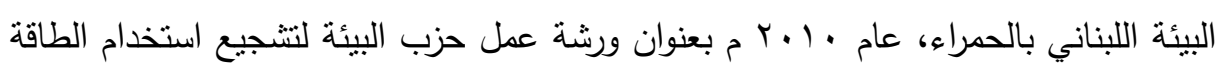
المتجددة وقد قدمت هذه الدراسات في دول مختلفة من العالم أجنبية وعربية ومحلية واستهدفت

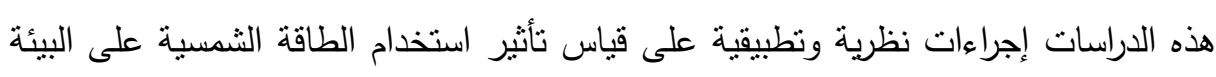
والتتمية المستدامة وللوصول لذلك قام الباحث بتتاول الطاقة الثمسية من ناحية مصادرها

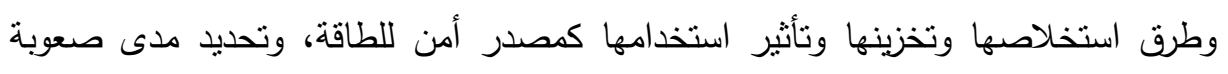

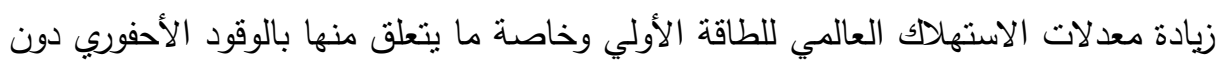

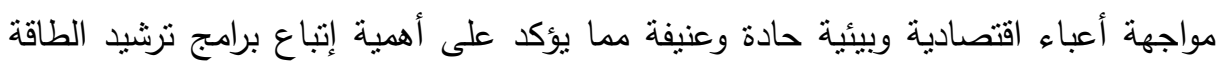

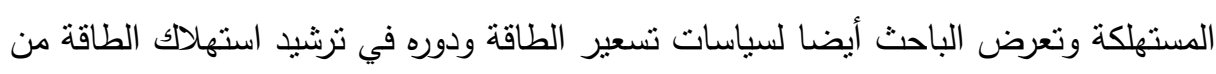

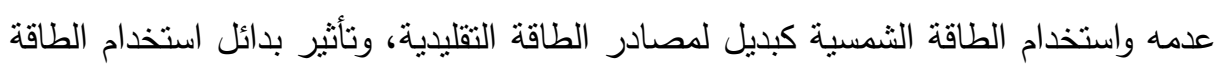
المتجددة على التلوث البيئي وقياس استخدام الطاقة الثمسية فكان هناك دعوة من الهيئة

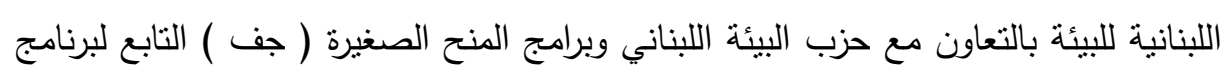
الأمم المتحدة الإنمائي أقيمت دراسة عمل تمهيدية أولى عن إمكانيات استخدام الطاقة المتجددة في لبنان.

\section{وقد خلصت الدراسات إلى عدة نتائج وتوصيات منها:}

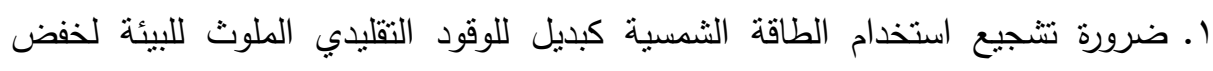

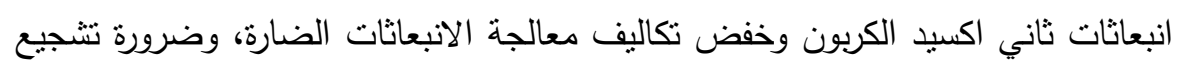

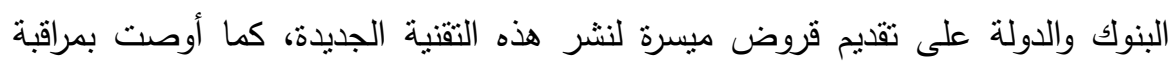
التلوث البيئي بالمشروعات الجديدة لتوليد الكهرباء سواء التقليدية أو المتجددة. 
r. ضرورة استخدام الطاقة الثمسية كبديل للطاقات التقليدية الملوثة للبيئة لذلك عند استخدام الطاقة الثمسية سوف نحافظ على البيئة، إن الطاقة الثمسية أقل نكلفة من استخدام الطاقة الكهربائية في الحصول على نفس القدر من الطاقة المطلوبة لتحلية المباهوالتكلفة البيئية التي يمكن توفيرها من خلال استخدام الطاقة الثمسية.

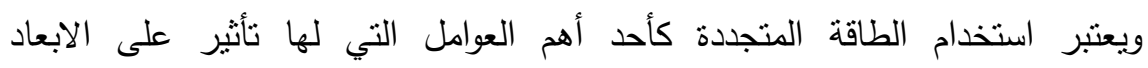
الاقتصادية والبيئية والصحية، وانطلاقا من الحاجة الماسة للاراسات في هذا المجال فان الدان مشكلة البحث الحالي تتجسد في كل من الآتي:

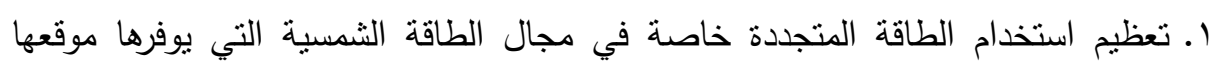
الجغرافي في نطاق الحزام الثمسي المدارى المحتوى لأطول فترات السطوع الثمسي

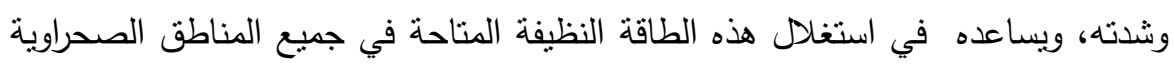
فتطبيق استخدام الطاقة الثمسية لازالت محدودة خاصة بالمدن الجديدة التي تقع جميعها

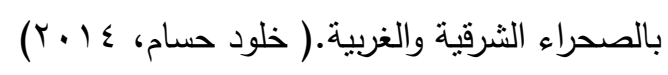

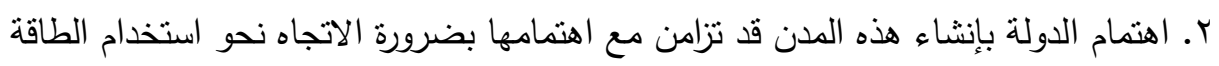
المتجددة ،تواجه المناطق الصحراوية والمناطق البعيدة عن المجاري المائية قلة في المياه المستخدمة في الزراعة لذلك تعتمد هذه المناطق على مياه الابار الجوفية، فالمصادر الجوفية تمثل المياه في حالة التخزين وقد تجمعت خلال قرون عديدة مع إضافات طفيفة من الأمطار الساقطة سنوياً وبذلك يتضح لنا أهمية المياه الجوفية كمصدر رئيسي يمكن فئن فئن أن يعتمد عليه إذا ما أحسن استغلاله لسد حاجة الإنسان والحيوان والنبات في مجالات التتمية الزراعية، في مطلع القرن الحالي ومع التطور الكبير في أدوات الحفر فقد تضافرت الفئن

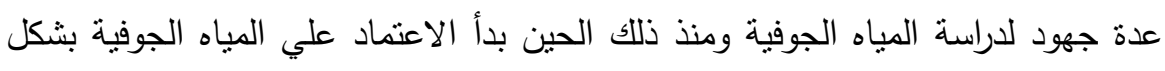

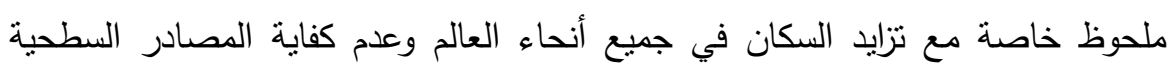

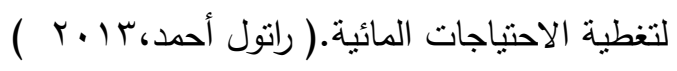

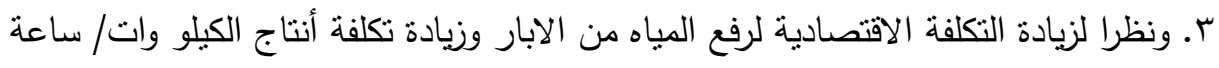

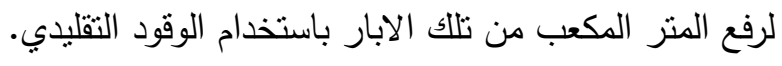

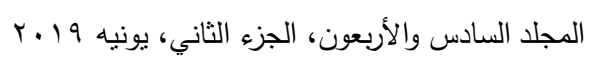




\section{أسئلا الترواسلة}

ما إمكانية تطبيق استخدام الطاقة المتجددة على رفع مياه الابار الجوفية بغرض الحفاظ على البيئة

ويتفرع من هذا التساؤل الرئيسي مجموعة الاسئلة الفرعية التالية:

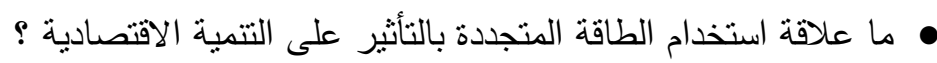

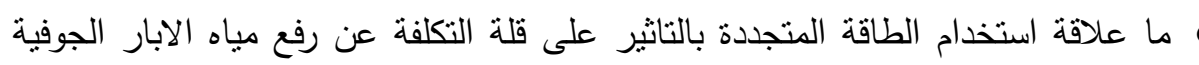

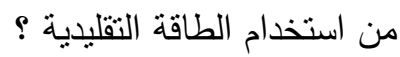
ها مدى تأثنير استخدام الطاقة المتجددة على كلا من التتمية المستدامة والبيئة ؟

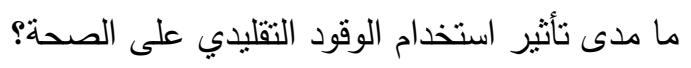

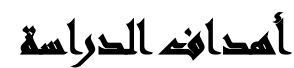

البحث عن افضل مصدر للحصول على الطاقة هل الطاقة المتجددة افضل ام الطاقة التقليدية ، فمن خلال هذا البحث سوف يتم توضيح تكلفة رفع المياه من الابار الجوفية

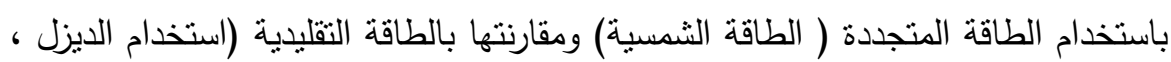

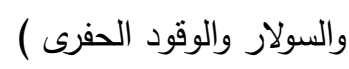

•وضيح مميزات وعيوب كل مصدر من مصادر الطاقة سوأ الطاقة المتجددة او الطاقة التقليدية وذلك بقياس تكلفة كلا منهما عند رفع المياه في عدة مناطق مختلفة على مستوى ونى الجمهورية ( الوادي الجديد، نوشكي وسيناء، وسط الدلتا، البحر الاحمر ، وادى النطرون)

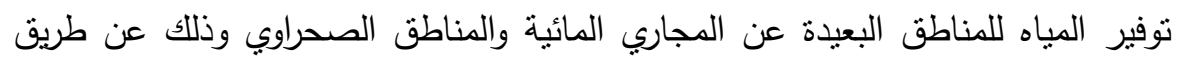
رفع المياه من الابار الجوفية لاستصلاح الأراضي الصحراوية وزيادة الرقعة الزراعية.

\section{هروضه التراسلة}

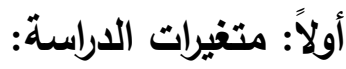

$$
\begin{aligned}
& \text { متغيرات مستقلة وهى :استخدام الطاقة المتجددة في رفع مياه الابار الجوفية } \\
& \text { ه البعد البيئي: مدى نأثير الطاقة المتجددة على البيئة }
\end{aligned}
$$

هالبعد الاقتصادي: النتائج الاقتصادية التي نحصل عليها باستبدال الوقود التقليدي بالمتجدد 
البعد الصحي: الاثار الصحية الناتجة عن استخدام الطاقة النقليدية والطاقة المتجددة

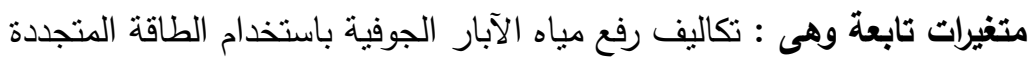

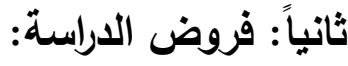
الفرض الرئيسي: توجد علاقة ذات دلاله إحصائية بين استخدام الطاقة المتجددة وخفض تكاليف رفع مياه الابار الجوفية بغرض الحفاظ على البيئة ولكى يمكن اختبار صحة هذا الفرض يمكن تحليله جزيئا لفروض فرعية: توجد علاقة ذات دلاله إحصائية بين الاثار الاقتصادية للطاقة المتجدة وخفض تكاليف

$$
\text { رفع مياه الابار الجوفية }
$$

هوجد علاقة ذات دلاله إحصائية بين الاثار البيئية للطاقة المتجددة وخفض تكاليف رفع

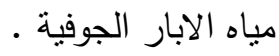

توجد علاقة ذات دلاله إحصائية بين الاثار الصحية للطاقة المتجدة وخفض تكاليف رفع

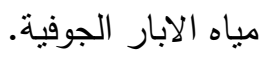

\section{مشوب الصواسمة}

الحدود الزمنية: يتم تحديد الحدود الزمنية من بداية القيام بالدراسة حتى الانتهاء منها تبدأ في

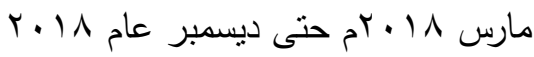
الحدود المكانية: منطقة وادى النطرون - المحطة التابعة لوزارة الموارد المائية والري التي تعمل بالخلايا الثمسية لرفع مياه الابار الجوفية.

\section{منهAي}

اتبع الباحثون الأسلوب الوصفي في التحليل عن طريق جمع البيانات والمعلومات والإحصائيات المتعلقة بموضوع الدراسة سواء من الكتب أو التقارير والدوريات والمؤتمرات

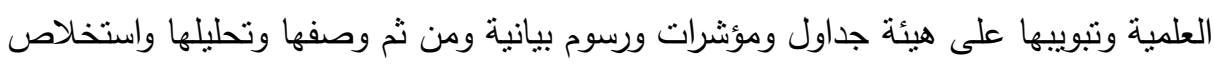

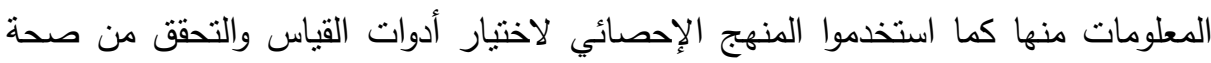
الفروض باستخدام الأساليب الإحصائية واستتباط النتائج وتفسيرها.

$$
\text { المجلد الساد والأربعون، الجزء الثاني، يونيه } 9 \text { بـ ب }
$$




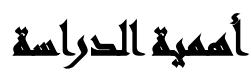

الوصول لاستخدام الطاقة الافضل من الناحية الاقتصادية والبيئية والصحية وذلك من

خلال المقارنة بين الطاقة المتجددة والطاقة التقليدية البحث عن افضل طرق لتوليد للطاقة لرفع مياه الابار الجوفية حتى سطح الارض بتكلفة

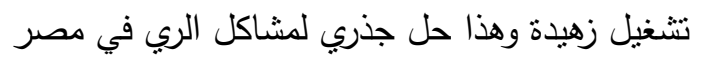
ه تخفيض تكاليف التشغيل وتكاليف الصيانة وبالتالي خفض تكلفة الكيلو / وات ساعة المولدة ، وكذلك خفض الآثار السلبية على البيئة . • الاستغلال الأمتل للطاقة الثمسية في مصر ، زيادة الاستثمارات الموجه للطاقة الثمسية.

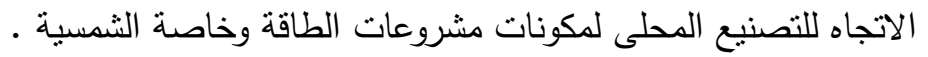
• الاشتراك القوى للقطاع الخاص في مشروعات واستثمارات الطاقة الثمسية . •الاستفادة من التجارب الناجحة في هذا المجال وخاصة التجربة الألمانية الرائدة. • تفعيل وترويج دور هيئة تتمية واستخدام الطاقة الجديدة والمتجدة الجهة الوحيدة والمتخصصة في مجال الطاقة النظيفة ومنها الثمسية.

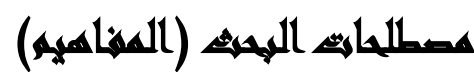

الطاقة والبيئة: نوجد مصادر متعددة لإنتاج الطاقة والتي تلعب أيضاً دوراً كبيراً في عملية التتمية ومنها النفط، الغاز الطبيعي، المخلفات الزراعية والحيوانية، الكهرباء، وقد كثر استخدام

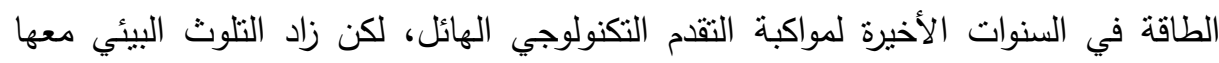
وخاصة بالنسبة لنلوث الهواء أو الماء مثل انبعاث الغازات الضارة مثل( ثاني أكسيد الكبريت،

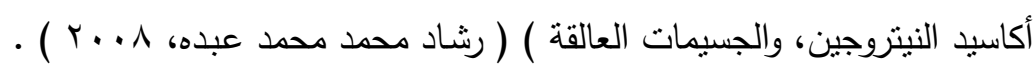
مفهوم الطاقة غير المتجددة: يطلق هذا المفهوم على جميع موارد الطاقة التي وفرت وساهمت في تغطية وتوفير كافة منطلبات احتياجات المجتمعات الصناعية المتطورة والعصرية من الطاقة، وتحوي( الفحم، البترول والغاز الطبيعي) وبالإضافة إلى الطاقة النووية، والتي 
تعتبر من الموارد الناضبة والمنتهية إذا ما استمر استغلالها بوتيرة ودرجة معينة مع مرور

$$
\text { الزمن ( سهير محمد طلعت الغزالي، و . . ب ). }
$$

مفهوم الطاقة المتجددة: هي كل طاقة يكون مصدرها شمسي، جيوفيزيائي أو بيولوجي والتي تتجدد في الطبيعة بوتيرة معادلة أو أكبر من نسب استعمالها، وتتولد من التبارات المتتالية والمتواصلة في الطبيعة، كطاقة الكتلة الحيوية والطاقة الثمسية وطاقة باطن الأرض، حركة المياه، طاقة المد والجزر في المحيطات وطاقة الرياح، ويوجد الكثير من الآليات التي تسمح بتحويل هذه المصادر إلى طاقات أولية، كالحرارة والطاقة الكهربائية، وإلى طاقة حركية باستخدام تكنولوجيات متعددة، تسمح بتوفير خدمات الطاقة من وقود

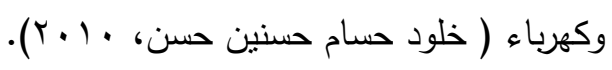

\section{السراسايس المابرية}

بعد المسح المكتبي لمختلف المراجع والمصادر المتعلقة بموضوع قياس أثز استخدام الطاقة المتجددة على تكاليف رفع مياه الابار الجوفية بغرض الحفاظ على البيئة لاحظنا أن الكتابة في هذا المجال كانت متوفرة نوعا ما، لكن تلك الدراسات تباينت من حيث الدار منهجية

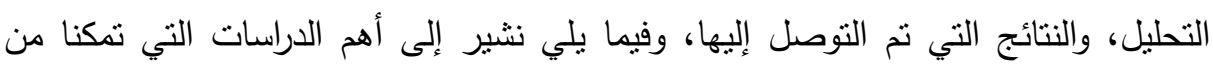
الاطلاع عليها:

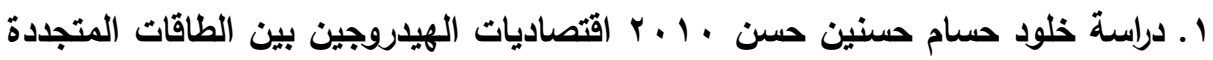

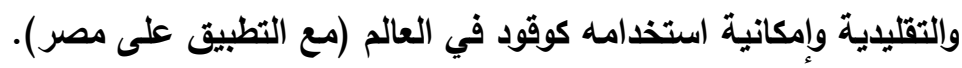

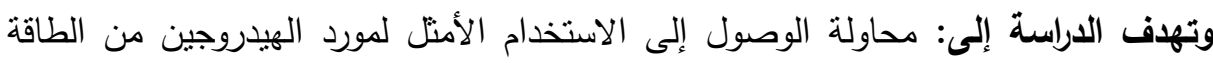

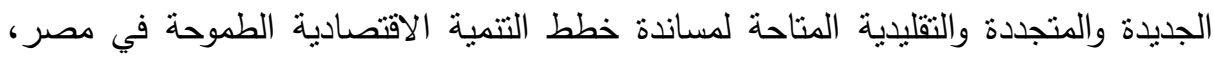
واكتثاف أساليب تقنية نظيفة لإنتاج الهيدروجين باستخدام الحفارات والطاقة المتجددة لإحداث ثورة في الطريقة التي نمد بها السيارات والمنازل والثركات التجارية بالطاقة، وإمكانية استخدام تللك الطاقة في تطبيقات النقل في مصر لهر 
توصلت الدراسة إلى النتائج التالية: أن فعالية الهيدروجين الاستهلاكية تبلغ ثلاث أضعاف

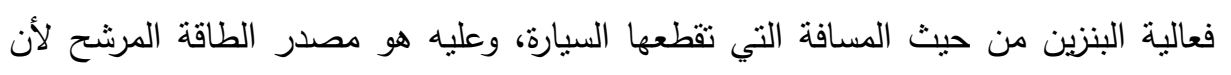

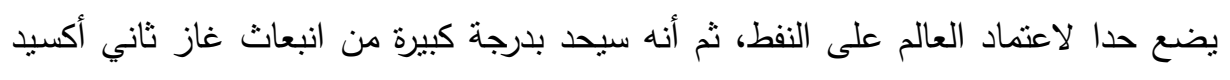
الكربون من عوادم السيارات، ويخفف من ارتفاع درجات الحرارة عالميا.

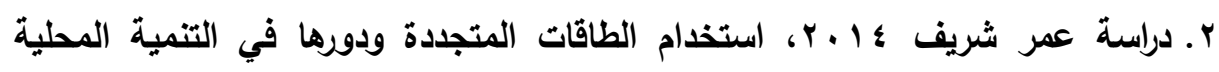
المستدامة (دراسة حالة الطاقة الشمسية في الجزائر)

وتهدف الاراسة إلى: التوصل إلى أحسن الطرق البديلة لإحلاد الطاقة التقليدية

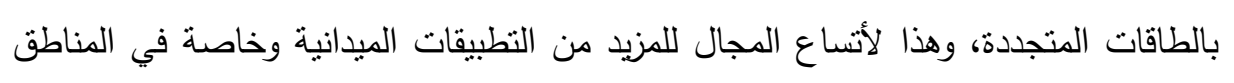
الريفية، إضافة إلى التقليل من الضغوطات المفروضة من الطرف المدني للتخلص من التلوث والحياة في بيئة نظيفة مستدامة. توصلت الدراسة إلى النتائج التالية: أن الطاقة النظيفة والمتجددة رغم إنتاجها أحيانا يكون

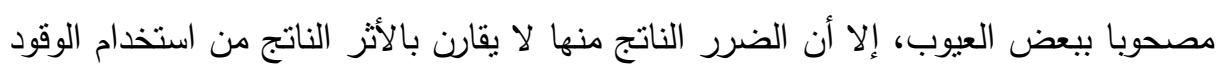

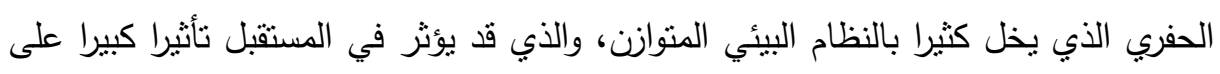

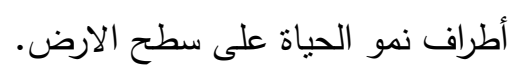

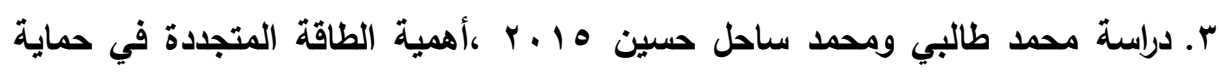

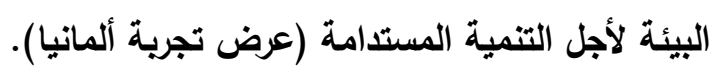

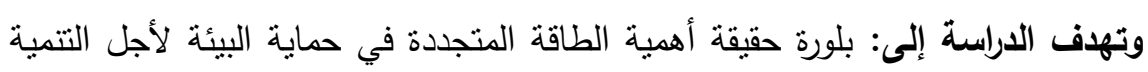

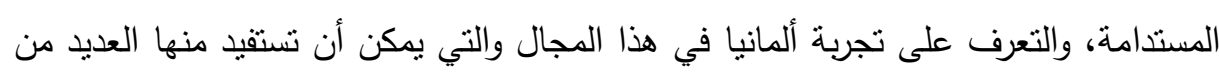
الدول النامية والتي منها الجزائر. توصلت الدراسة إلى النتائج التالية: أن ألمانيا تشهد ازدهارا كبيرا في مجال الطاقة المتجددة،

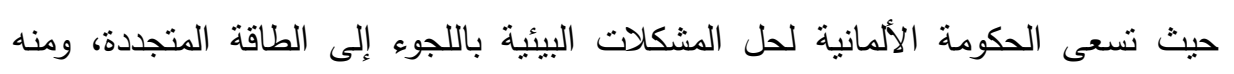
التقليل من استخدام الطاقة التقليدية والحد من انبعاثات الغازات الضارة من أكسيد الكربون بالثئ والنيتروجين والكبريت. 
ـ ـ دراسة بوعافية رشيد 1 ـ ب ، استراتيجية الطاقة والبيئة في ظل التنمية المستدامة بالجزائر .

توصلت الدراسة إلى النتائج التالية: أن الجزائر اعتمدت بعدين أساسيين من أجل تحقيق استراتيجيتها طاقوية، تعلق الأول بأولويات الاستجابة للمتطلبات الداخلية وتحقيق الإطار

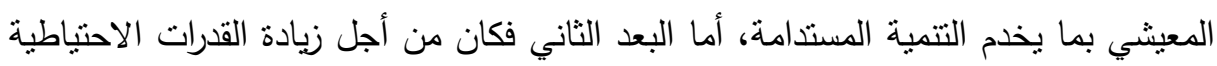
للجزائر من خلال دعم الثراكة الدولية واستقطاب رؤوس الأموال الأجنبية والتكنولوجيا الحديثة، وما ميز هذه الاستراتيجية عن الاستراتيجيات السابقة للجزائر كونها لم تغفل البعد البدابله

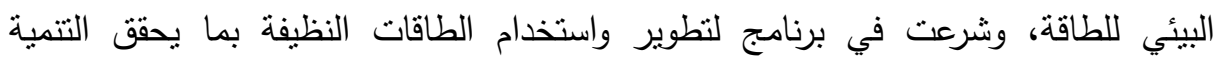
المستخامة، وعززت ذللك بإطار تتظيمي وتنريعي لتنفيذ هذه الاستراتيجية. 2013 , World Energy Resources، .0

وتهدف الدراسة إلى : التطرق الى تقرير مصادر الطاقة العالمية الصادر عن مجلس الطاقة

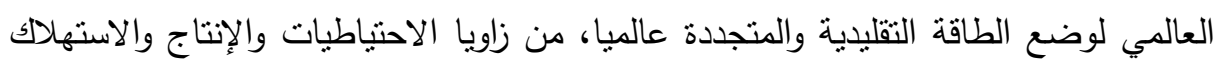

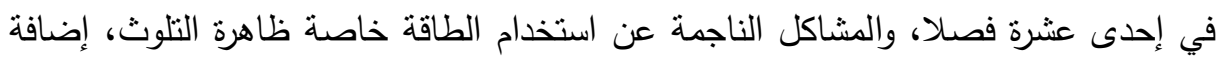
إلى مسألة نضوب المصادر الطاقة التقليدية، وكذا مسألة الاستفادة من مصادر الطاقية الطاقة المتجددة والبديلة للطاقة التقليدي وتوصلت الدراسة إلى النتائج التالية: أن المصادر المتجددة مساهمتها ضعيفة جدا من إجمالي إنتاج واستهلاك الطاقة في العالم مقارنة بالمصادر التقليدية.

\section{الإطار اللنظيه}

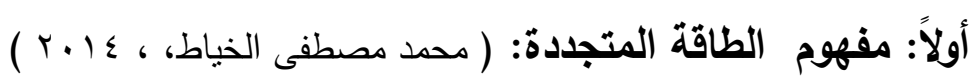
الطاقة المتجددة هي كل طاقة يكون مصدرها شمسي، جيوفيزيائي أو بيولوجي والتي تتجدد في الطبيعة بوتيرة معادلة أو أكبر من نسب استعمالها، وتتولد من التيارات المتتالية والمتواصلة في لئي الطبيعة، كطاقة الكتلة الحيوية والطاقة الثمسية وطاقة باطن الارض، حركة المياه، طاقة المجد والجزر فى المحيطات وطاقة الرياح، ويوجد الكثير من الاليات التى تسدح بتحويل هذه

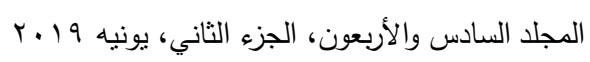


الدصادر الى طاقات اولية ، كالحرارة والطاقة الكهربائية، والى طاقة حركية باستخدام تكنولوجيات متعددة، تسمح بتوفير خدمات الطاقة من وقود وكهرباء .

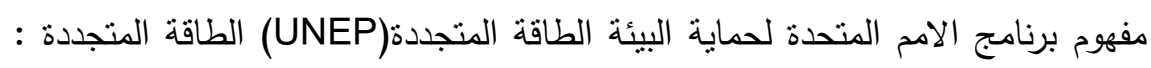
هى عبارة عن طاقة لا يكون مصدرها هي عبارة عن طاقة مخزونا ثابتا ومحدودا فى الإنى الطبيعية ، تتجدد بصفة دورية أسرع من ونيرة استهلاكها، وتظهر في الأشكال الخمسة التالية:

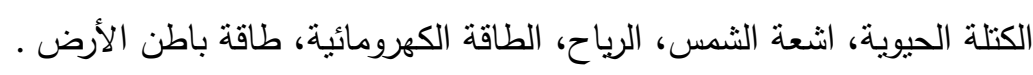

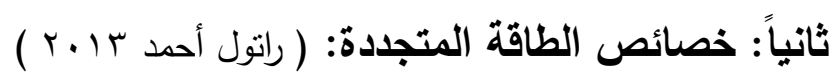
تتميز الطاقات المتجددة بعدة خصائص نذكر أهمها فيما يلى:

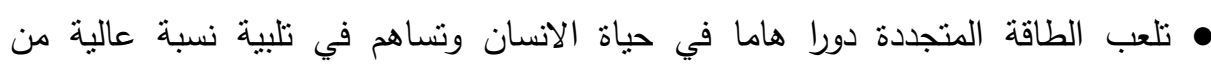

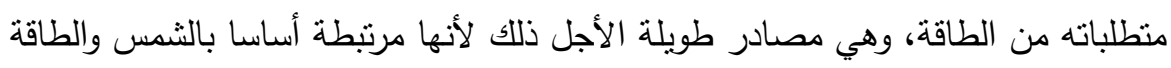
الصادرة عنها. الطاقة المتجددة ليست مخزونا جاهزا نستعمل منه ما نشاء منى نشاء فمصادر الطاقة

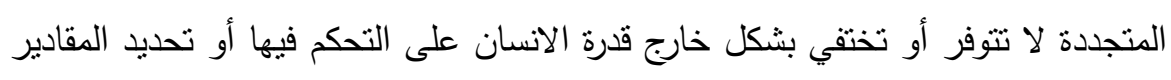

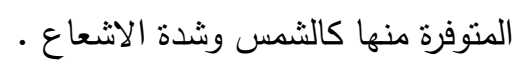
ه استخدام مصادر الطاقة المتجددة يتطلب استعمال العديد من الأجهزة ذات المساحات

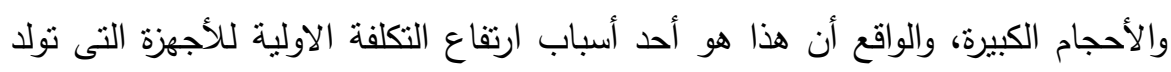

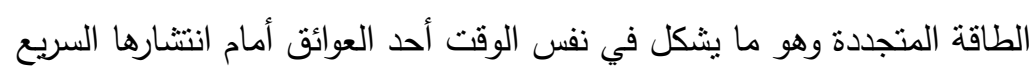
توفر أثنكال مختلفة من الطاقة في مصادر الطاقة المتجددة الأمر الذي يتطلب استعمال تكنو لوجيا ملائمة لكل شكل من الطاقة.

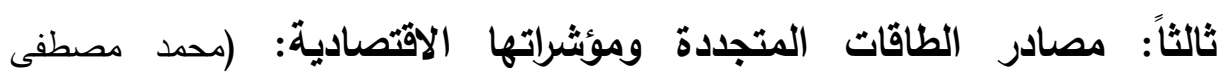

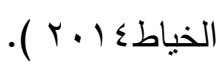

تعتبر الثمس المصدر الرئيسي لكثير من مصادر الطاقة الموجودة فى الطبيعة، حتى

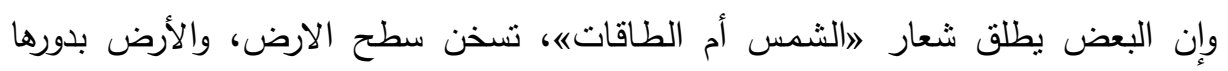

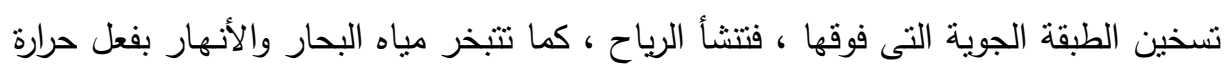
الثمس، فتتكون السحب ونحصل على الأمطار والثلوج، وإلى جانب طاقتي الثمس والرياح 276

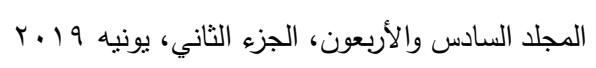


توجد طاقة المد والجزر، وحرارة باطن الأرض، وطاقة العيدروجين وغيرها ويطلق على هذه

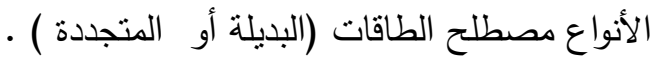

\section{رابعاً: أهمية الطاقة المتجدة في حماية البيئة لأجل التنمية المستدامة:}

أصبحت البيئة اليوم عنصرا من عناصر الاستغلال العقلاني للموارد ومتغيرا أساسيا من لنه

متغيرات التتمية المستدامة، نظرا لما يحدثه التلوث من انعكاسات سلبية على المناخ من جهة

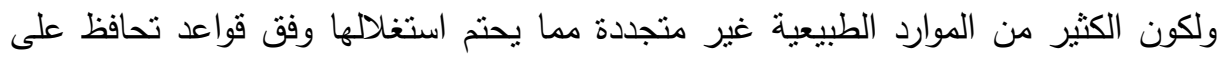

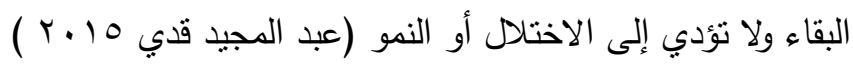

إن من أهم التأثيرات البيئية المرتبطة باستخدامات الطاقة التقليدية ما يعرف بظاهرة

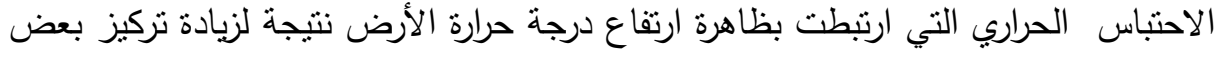

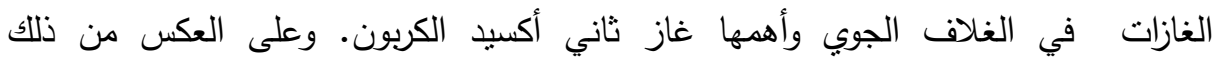
فلاستخدام الطاقة المتجددة أثز معروف في حماية البيئة نتيجة لما تحققه من خفض انبعاث

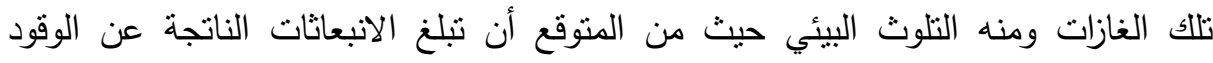

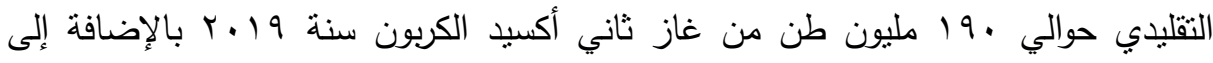
الغازات الأخرى. كذلك في تقرير أصدرته شبكة سياسة لطاقة المتجددة للقرن الواحد والعشرين (آر إي أن (Y) يقول بأنه يجب أن تلعب الطاقة المتجددة دورا رئيسيا في إمدادات الطاقة العالمية وذلك من أجل مواجهة التهديدات البيئية والاقتصادية للتغير المناخي التي تنزايد خطرا

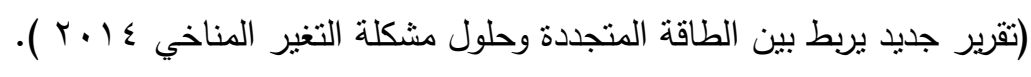
في هذا الإطار نوقع خبراء ألمان تفاقم أزمة الطاقة خلال السنوات القليلة المقبلة (الطاقة

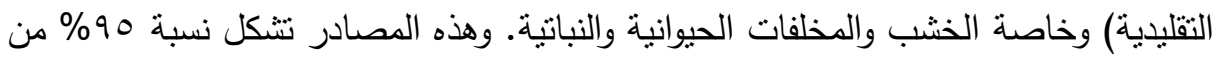

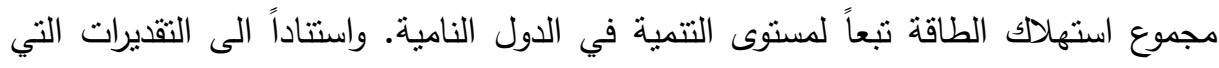

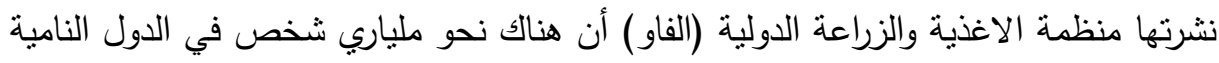

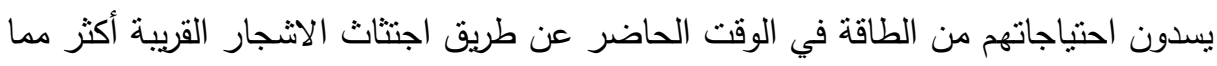

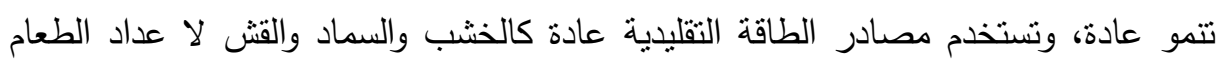
وتسخين المياه والتدفئة وحسب التقديرات ذاتها فان متوسط الاشجار والغابات القريبة من المدن

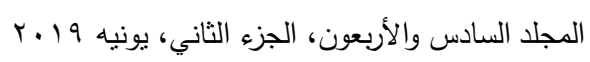


والمناطق السكنية نتراجع بصورة مستمرة، هذا بالإضافة الى ما يسببه ذلك من جفاف في

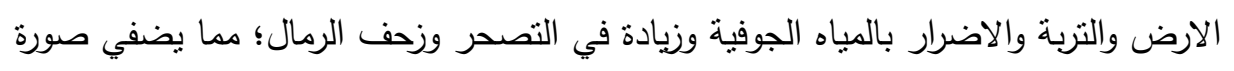
كئية للعالم بسبب ازدياد معدلات غاز ثاني أكسيد الفحم وأن احتراق مصادر الطاقة المنجمية

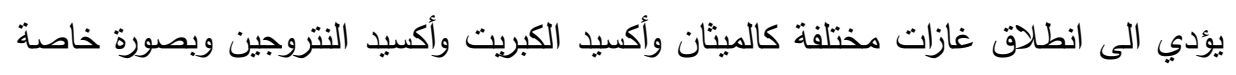
أكسيد الفحم التي تتسبب بصورة كبيرة في مشكلة انحباس الحرارة، ويرى "تسافا تسكي" الخبير

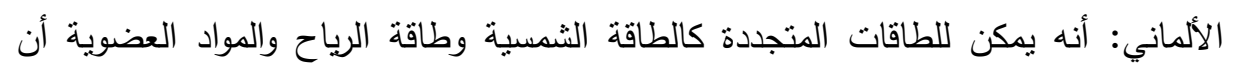

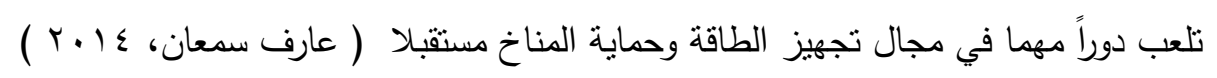
خصوصا وأن تكلفة توليد الكهرباء من مصادر الطاقة المتجددة آخذت في النقصان

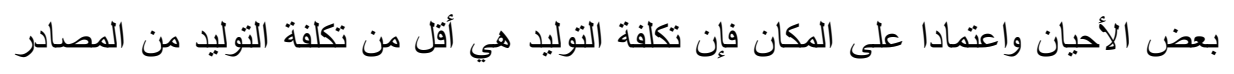

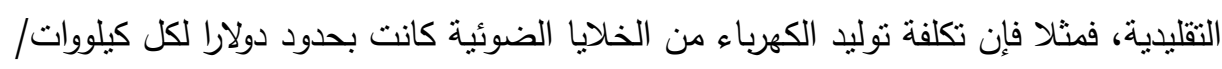

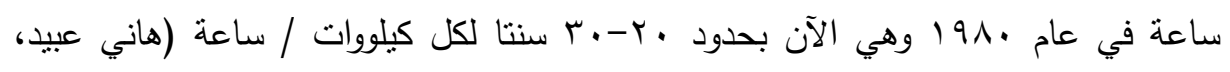
$(r \cdot 10$ مما سبق نستتج أن للطاقة المتجددة أهمية بالغة في حماية البيئة باعتبارها طاقة غير ناضبة وتوفر عامل الأمان البيئي.

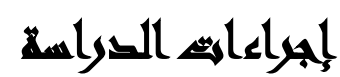

الاراسة الميدانية وإجراءاتها :الأداة المستخدمة للحصول على المعلومات

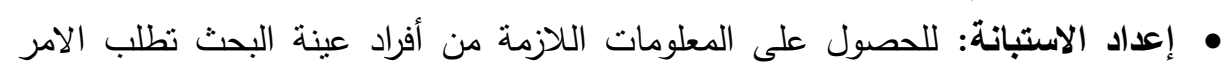
تصميم استبيان بناء على أهداف البحث ومتغيراته واستلمت هذه الاستبانة على جزئين الانين

$$
\begin{aligned}
& \text { على النحو التالي: } \\
& \text { الجزء الأول: البيانات الأساسية }
\end{aligned}
$$

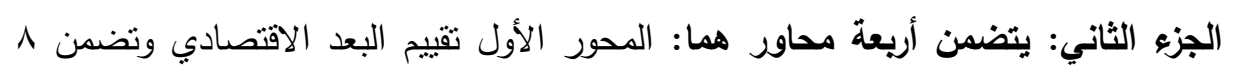

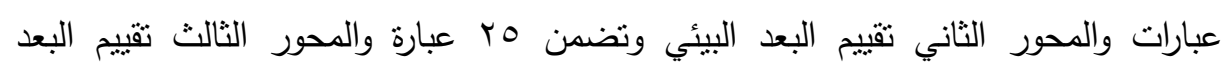

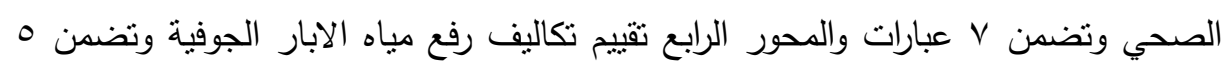


واتبع الباحثون الأسلوب الوصفي في التحليل عن طريق جمع البيانات والمعلومات

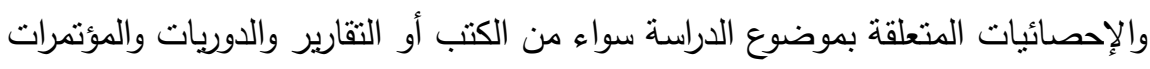
العلمية وشبكة المعلومات الدولية وتبويبها على هيئة جداول ومؤشرات ورسوم بيانية ومن لدواهن

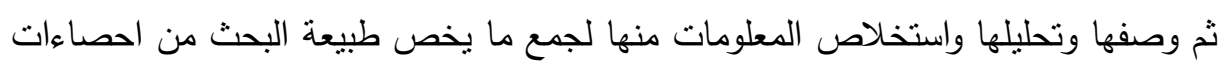
ومنشورات.

كما استخدم المنهج الإحصائي لاختيار أدوات القياس والتحقق من صحة الفروض باستخدام الأساليب الإحصائية واستتباط النتائج من خلال تفسيرها. اختبار ثبات وصدق الاستبانة: نم حساب معامل الثبات (Cronbach Alpha) لأسئلة الاستقصاء في كل فئة من فئات الدراسة، وذلك لبحث مدى ثبات أسئلة الاستبيان وكذلك لبحث مدى إمكانية الاعتماد على هذه الأسئلة في التحليل وكانت قيم معاملي الصدق ودى والثبات

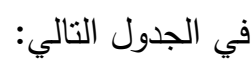
جدول رقم (1): معاملات الصدق والثبات لإجمالي أبعاد قياس أثر استخدام الطاقة المتجددة على العي

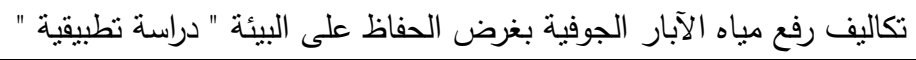

\begin{tabular}{|c|c|c|}
\hline الصدق & الثبـات & 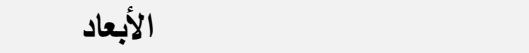 \\
\hline$\cdot, \wedge 95$ & $\cdot, \mathrm{V} 9 \mathrm{~V}$ & الاثار الاقتصادية لاستخدام الطاقة المتجددة \\
\hline$\cdot, 9 \cdot 1$ & $\cdot$, A ro & الاثار البيئية لاستخدام الطاقة المتجددة \\
\hline$\cdot, \wedge \wedge 1$ & $\cdot, \mathrm{V} \vee \mathrm{V}$ & الاثار الصحية لاستخدام الطاقة المتجددة \\
\hline 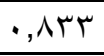 & $\cdot, 790$ & تكاليف رفع مياه الآبار الجوفية \\
\hline$\cdot, 9 \cdot \varepsilon$ & $\cdot, \wedge \backslash \wedge$ & إجمالي المقياس \\
\hline
\end{tabular}

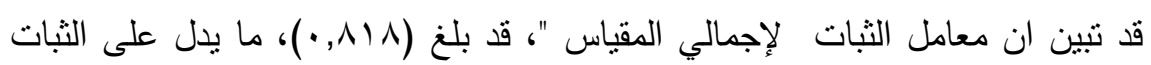

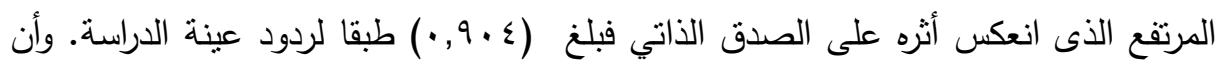

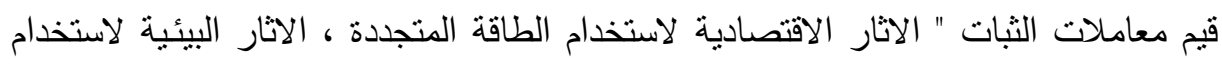

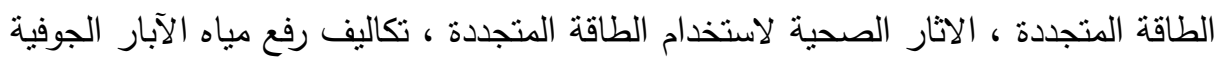

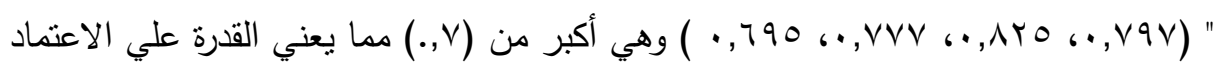
علي تلك المقاييس. 
أن قيم معاملات " الصدق " الاثار الاقتصادية لاستخدام الطاقة المتجددة ، الاثار البيئية لاستخدام الطاقة المتجددة، الاثار الصحية لاستخدام الطاقة المتجددة ، تكاليف رفع مياه الآبار

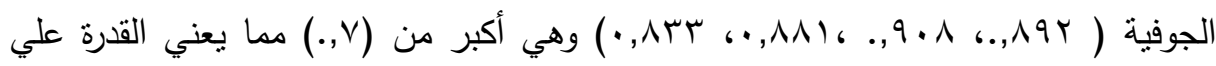
الاعتماد علي تلك المقاييس.

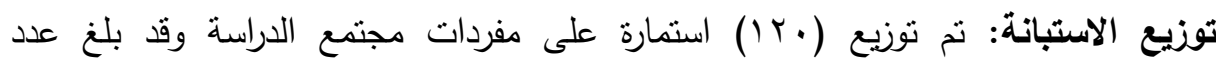

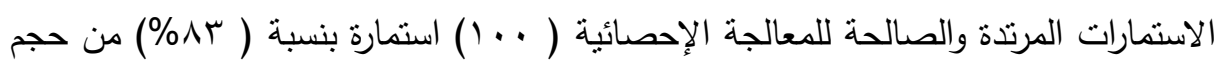

جدول (ץ): التكرارات والنسب المئوية لعينة الدراسة لمتغير المستوى التعليمي

\begin{tabular}{|c|c|c|}
\hline النسبة & العدد & المستوى التعليمي \\
\hline$\varepsilon, \Gamma$ & $\varepsilon$ & مؤهل متوسط \\
\hline 7,0 & 7 & مؤهل فوق المتوسط \\
\hline$r \cdot, 1$ & $r \Lambda$ & مؤهل عالى \\
\hline$\Lambda, 7$ & $\Lambda$ & دراسات عليا \\
\hline$r \varepsilon, V$ & rr & ماجستير \\
\hline$r_{0, \Lambda}$ & $r \varepsilon$ & دكتوراه \\
\hline $1 \ldots$ & 94 & الإجمالي \\
\hline
\end{tabular}

يوضح الجدول السابق توزيع عينة الدراسة من حيث المؤهل العلمي حيث احتل مؤهل

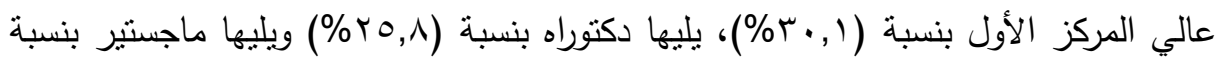
(\% \% \&,V) مؤهل متوسط بنسبة (r, ؟ \%).

جدول(ץ): التكرارات والنسب المئوية لعينة الدراسة لمتغير الحالة الوظيفية

\begin{tabular}{|c|c|c|}
\hline النسبة & العدد & الحالة الوظيفية \\
\hline$\varepsilon V, r$ & $\varepsilon \varepsilon$ & خبير \\
\hline Yq, & TO & مستثر \\
\hline$r_{\cdot,, \varepsilon}$ & 19 & مصنع \\
\hline $0, \varepsilon$ & 0 & مزارع \\
\hline $1 \ldots$ & 94 & الإجمالى \\
\hline
\end{tabular}

يوضح الجدول السابق نوزيع عينة الدراسة من الحالة الوظيفية حيث كانت وظيفة خبير

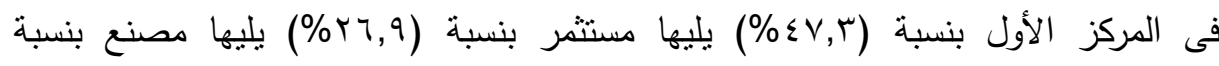

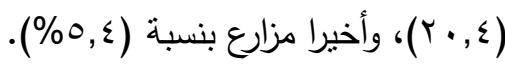




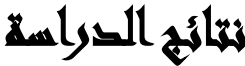

المجموعة الأولى: الأسئلة التي تستخدم لقياس المتغير المستقل الأول استخدام الطاقة

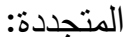

جدول رقم (؛): الأهمية النسبية والمنوسطات الحسابية لقياس الآثار الاقتصادية لاستخدام

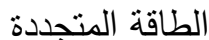

\begin{tabular}{|c|c|c|c|c|}
\hline الأرمية & 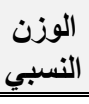 & المعياري & المتوسط & العبارة \\
\hline r & $97, \wedge$ & $\cdot, r 9 \vee$ & r,q. & 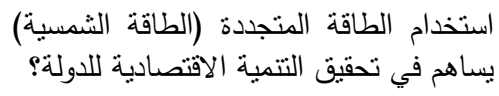 \\
\hline$r$ & $97, \%$ & • & $r, \wedge q$ & 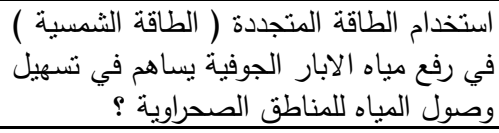 \\
\hline 1 & 99,7 & $\cdot, 1 \cdot \varepsilon$ & $r, 99$ & 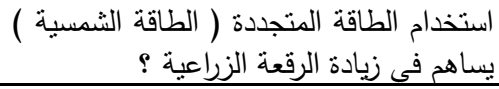 \\
\hline 0 & $9 Y, \Lambda$ & זוד, - ב ב ב ב ב & $r, \mathrm{r} \wedge$ & في محطات الرفع وعمق بئر المياه الجوفية؛ المبكة \\
\hline$\varepsilon$ & $90, \mathrm{~V}$ & $\cdot, \leqslant 9 \leqslant$ & $r, \Lambda V$ & 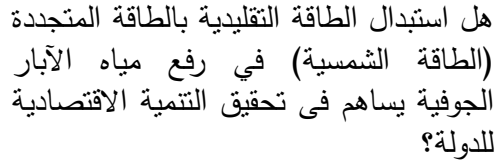 \\
\hline$\wedge$ & VY, $\varepsilon$ & שד & r,IV & والمشروعات للحفاظ على البيئة ؟ بماً للشركات \\
\hline 1 & $\Lambda \Lambda, r$ & $\cdot,(17)$ & $r, 10$ & 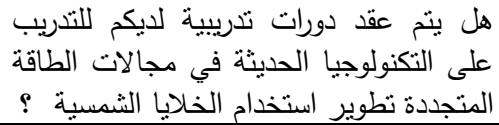 \\
\hline $\mathrm{v}$ & $\Lambda \mathrm{v}, \Lambda$ & $\cdot, \vee>9$ & r זד, r & عاجزة تواجه تطبيق القرات مشكلات البيئة مالية تجعلها \\
\hline- & - & $\cdot, v \backslash 1$ & $Y, Y \varepsilon$ & أجمالي الآثار الاقتصادية \\
\hline
\end{tabular}

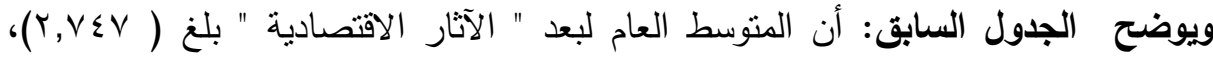
والانحراف المعياري (VII,_(·)، ويعد أكثر العناصر موافقة في الآثار الاقتصادية هو:

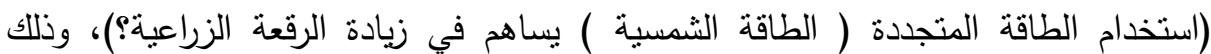

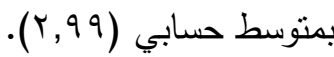


وقد كان اقل عنصر موافقة في بعد الآثار الاقتصادية هو (هل تقدم الحكومة دعماً

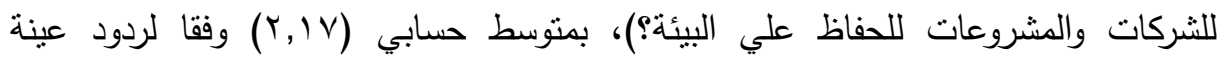
الدراسة.

جدول رقم (•): الأهمية النسبية والمتوسطات الحسابية لقياس (الآثار البيئية )

\begin{tabular}{|c|c|c|c|c|}
\hline ترتيبة & الاختلاف - معل & 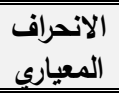 & المتوسط & العبارة \\
\hline r & $9 \wedge, 7$ & $\cdot, r q Y$ & r, १T & هل المستخدامة ؟ الطاقة المتجددة بحقق التتمية \\
\hline 1 & $99, r$ & $\cdot, r \cdot V$ & $r, 91$ & هل الحفاظ على البيئة ؟ الطاقة المتجددة يعمل على \\
\hline $1 \varepsilon$ & $\wedge r, q$ & $\cdot, \wedge r q$ & r,Or & 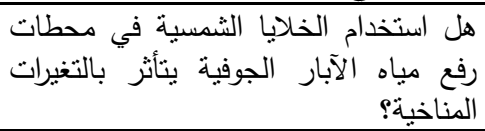 \\
\hline 1. & $91, \varepsilon$ & $\cdot, 701$ & $r, V \leqslant$ & 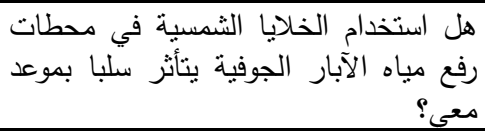 \\
\hline rI & Vr, V V & $\cdot, 00 \leqslant$ & $r, 11$ & هل البيئة؟ استخدام الطاقة الثمسية تؤثر على \\
\hline 0 & $9 \wedge, 7$ & •, rqY & r, 97 & في رفع مباه الآبار الجوفية الثمسية كطاقة متجددة \\
\hline 7 & $9 \wedge, 7$ & $\cdot, r q r$ & r,97 & بالبيئة؛ الطاقة التقليدية كالديزل والسولار ضاره \\
\hline 11 & $q \cdot, V$ & • TAY & r,Vr & 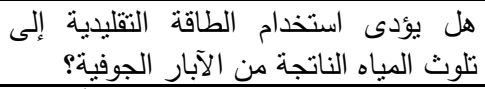 \\
\hline$r$ & $9 \wedge, 7$ & $\cdot, r q Y$ & $r, 97$ & هل البيئة؟ الطاقة التقليدية تسبب ضرراً على \\
\hline 9 & $9 r, \wedge$ &., 7.0 & $r, V \wedge$ & 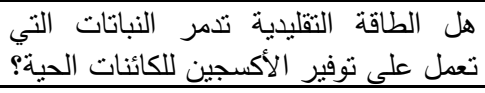 \\
\hline$\varepsilon$ & $97, \wedge$ & • rqY & $r, q$. & هل الطاقة التقليدية تؤدى إلى ظاهرة تآكل \\
\hline 11 & $\vee \wedge, q$ & $\cdot, 94$. & $r, r V$ & كمية المياه المستخرجة الطاقة التقليدية تؤثر الآبار الجوفية على \\
\hline V & 97,1 & • & $r, \wedge \Lambda$ & الموارد الطبيعية؟ الطاقة التقليدية يؤدى إلى نضوب \\
\hline 17 & $\wedge r, 1$ & $\cdot, \wedge \vee q$ & $r, \Sigma T$ & 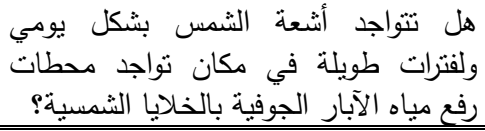 \\
\hline
\end{tabular}


مجلة العلوم البيئية

معهد الدراسات والبحوث البيئية - جامعة عين شمس لبه

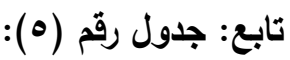

\begin{tabular}{|c|c|c|c|c|}
\hline ir & $9 \cdot, 7$ & $\cdot, \vee \cdots$ & Y,VY & 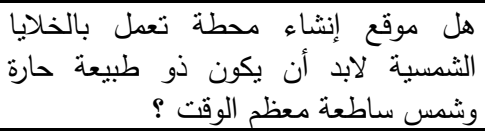 \\
\hline$\wedge$ & $90, r$ & $\cdot, 0, r$ & 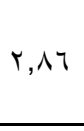 & ترفع من درجة الإسراف في استخدام الطاقة التقليدية \\
\hline rt & 71,1 & $\cdot, 9 \wedge \wedge$ & $r, \cdot \Sigma$ & هل لديك معلومات عن القوانين البيئية ؟ \\
\hline r. & $\vee 1, \cdot$ & $\cdot, 9 \wedge 1$ & $r, 1 r$ & هل يوجد رقابة بيئية على رفع مباه الآبار \\
\hline$r \leq$ & $7 \cdot, 7$ & $\cdot, 9 \vee V$ & $1, \lambda r$ & هل ينت عقد دورات تدرييية لديكم للتوعية \\
\hline r & $\pi$ & $\cdot, 907$ & 1,9 & هل تعلم ان هناك معايير بيئية عالمية ؟ \\
\hline ro & $\leqslant 9,0$ & $\cdot, 7 \cdot 1$ & $1, \varepsilon \wedge$ & وفنياً تم فحص المنشأة قبل بدء النشاط بيئيأ \\
\hline 19 & $\vee 0, r$ & $\cdot, 977$ & $r, Y \uparrow$ & هل هلت ينتج من للطاقة لاستخراج مياه الآبار الجوفية لأساليب \\
\hline iv & $\wedge 1, \cdot$ & $\cdot, \wedge \vee \vee$ & $r, \varepsilon r$ & المنشأة؟ توضع القوانين البيئية ضمن لوائح \\
\hline 1 & Nr, $q$ & $\cdot, \wedge \leqslant r$ & r,Or & لوائح المنشأةب؟ تطبيق القوانين البيئية مع تطبيق \\
\hline 10 & $\wedge r, \varepsilon$ & $\cdot, \wedge T \vee$ & $r, \varepsilon \vee$ & القواعد والقوانين البيئية؟ العليا للمنشأة بتطبيق \\
\hline & & $\cdot, 907$ & $r, \varepsilon \wedge$ & أجمالي الآثار البيئية \\
\hline
\end{tabular}

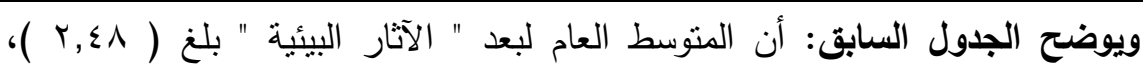

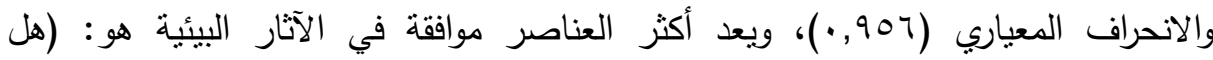

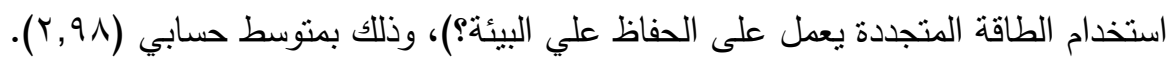

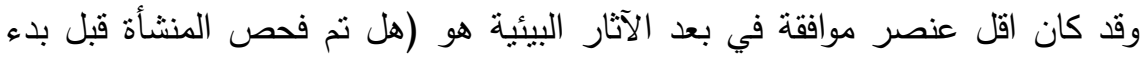

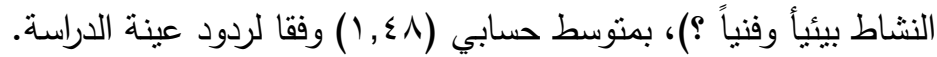


جدول رقم (7): الأهمية النسبية والمتوسطات الحسابية لقياس عنصر (الآثار الصحية)

\begin{tabular}{|c|c|c|c|c|}
\hline ت الأهمية & 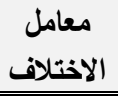 & 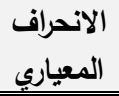 & المتوسط & العبارة \\
\hline 7 & $\varepsilon \varepsilon, \varepsilon$ & $\cdot, V \leqslant r$ & $1, \pi$ & هل الطاقة المتجددة تؤثر على صحة الإنسان ؟ \\
\hline 1 & $99, \mathrm{r}$ & $\cdot, r \cdot V$ & r,91 & هل الإنسان؟ الطاقة التقليدية كالديزل والسولار ضارة على صحة \\
\hline r & $\wedge \uparrow,$. & $\cdot, \vee \vee 9 \wedge$ & $r, 01$ & 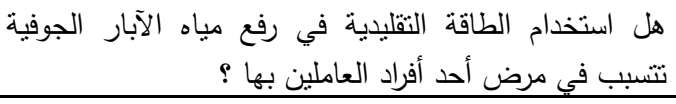 \\
\hline r & $9 \wedge, \mathrm{r}$ & $\cdot, 1 \cdot \varepsilon$ & $r, 90$ & في مرض الحسام الطاقة التقليدية في رفع مياه الآبار الجوفية تتسبب \\
\hline ० & 09,1 & • & l, VV & في أمرض الطين التقليدية في رفع مياه الآبار الجوفية تتسبب \\
\hline$\varepsilon$ & $V Y, \varepsilon$ & $\cdot, 711$ & r, r r & في أمرض الجهام الطاقة التقليدية في رفع مياه الآبار الجوفية تتسبب \\
\hline $\mathrm{v}$ & ro,r & $\cdot, r 00$ & $1, .7$ & في الأمراض الطاقة النقليدية في رفع مياه الآبار الجوفية تتسبب \\
\hline & & $\cdot, 0$ or & $r, 10$ & أجمالي الآثار الصحية \\
\hline
\end{tabular}

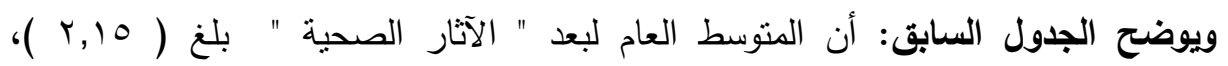

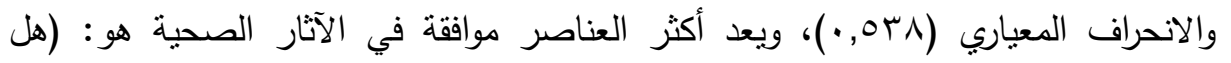

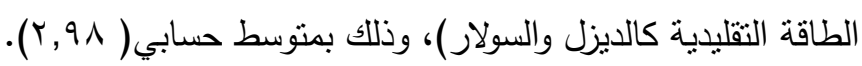
وقد كان اقل عنصر موافقة في بعد الآثار الصحية هو (استخدام الطاقة التقليدية في رفع

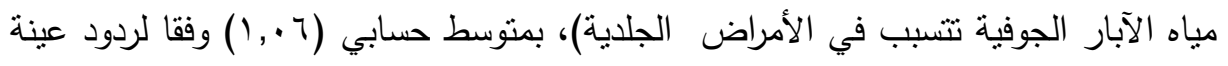
الدراسة. 
المتغير التابع: التكلفة جدول رقم(V): الأهمية النسبية والمتوسطات الحسابية لقياس عنصر (تكاليف رفع مياه الابار

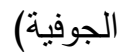

\begin{tabular}{|c|c|c|c|c|}
\hline ترتيبّ & الاختلاف & 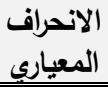 & المتوسط & 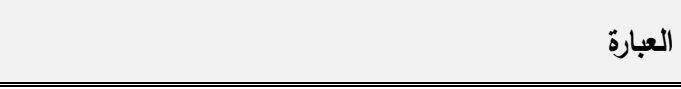 \\
\hline 0 & $\vee \wedge, \cdot$ & $\cdot, 0 \leq V$ & $r, r \leqslant$ & المحطاتة التحطات التي تعمل بالوقود التقلبدي بالطاقة الثمسية اقل تكلفة من \\
\hline 1 & $99, \Gamma$ & $\cdot, 1 \leq 7$ & $r, 9 \wedge$ & 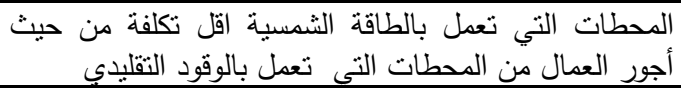 \\
\hline r & $90, \mathrm{~V}$ & $\cdot, \leq 9 \leq$ & r,AV & 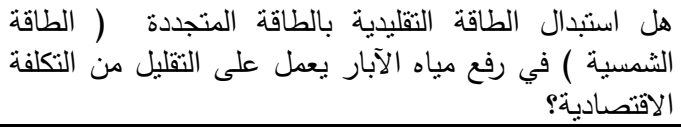 \\
\hline$\varepsilon$ & $\wedge \vee, \wedge$ & $\cdot, \vee \vee V$ & $r, \tau$ & 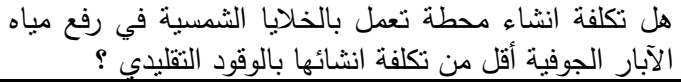 \\
\hline r & $9 \uparrow, 9$ & $\cdot, 0 \mathrm{~V}$ & r,Ar & 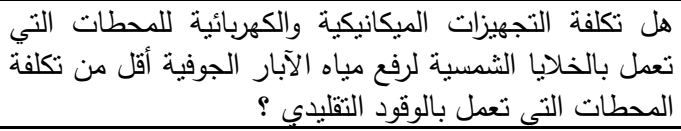 \\
\hline & & $\cdot, \varepsilon \cdot V$ & $r, \mathrm{VA}$ & أجمالي تكاليف رفع مياه الآبار الجوفية \\
\hline
\end{tabular}

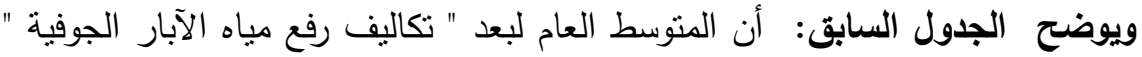

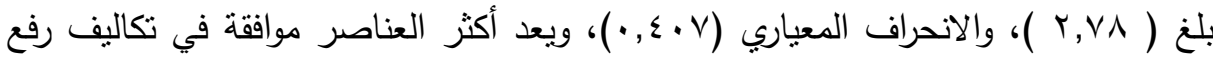
مياه الابار الجوفية هو: (المحطات التي تعمل بالطاقة الثمسية اقل تكلفة من حيث أجور العمال من المحطات التي تعمل بالوقود التقليدي )، وذلك بمتوسط حسابي (؟,9^). وقد كان اقل عنصر موافقة في بعد تكاليف رفع مياه الابار الجوفية هو (صيانة

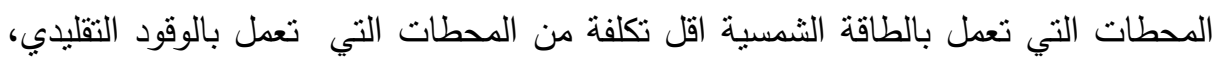
بمتوسط حسابي ( ع r, و) وفقا لردود عينة الدراسة.

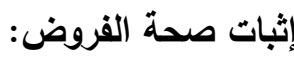

الفرض الرئيسي الأول: توجد علاقة ذات دلاله إحصائية بين استخدام الطاقة المتجددة على تكاليف رفع مياه الابار الجوفية بغرض الحفاظ على البيئة ويتفرع منه الفروض الآتية: ا.فرض فرعى أول: ماهي الآثار الاقتصادية للطاقة المتجددة للطاقة المتجددة على تكاليف

$$
\text { رفع مياه الابار الجوفية }
$$


Simple regression الأسلوب الإحصائي المستخدم : تحليل الانحدار البسيط

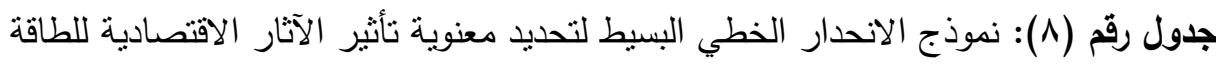
المتجددة، وتكاليف رفع مياه الآبار الجوفية لاحلية

\begin{tabular}{|c|c|c|c|c|c|c|}
\hline \multirow[b]{2}{*}{ R2 } & \multicolumn{2}{|c|}{ F. test } & \multicolumn{2}{|c|}{ t. test } & \multirow{2}{*}{ المجرةة } & \multirow[b]{2}{*}{ المتغير المستقل } \\
\hline & المعنوية & القيمة & المعنوية & القيمة & & \\
\hline$\% \circ 9, \cdot$ & $* *,, \ldots 1$ & $V \leqslant \wedge, \cdot \varepsilon$ & $* *,,+1$ & $1 K, \leqslant 79$ & $9, Y \wedge \vee$ & الجزء الثابت \\
\hline & & & $* *, \cdot, 1$ & $r V, 1 T V$ & איז 1, & للآثارة الاقتصدادية \\
\hline
\end{tabular}

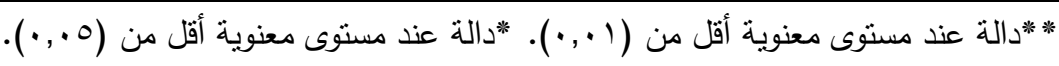

يتضح من الجدول السابق مجموعة من النتائج التي تم التوصل إليها:

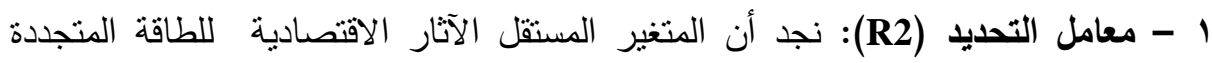
يفسر (•,9\%\%) من التغير الكلي في المتغير التابع (تكاليف رفع مياه الآبار الجوفية).

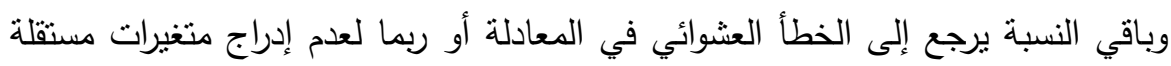

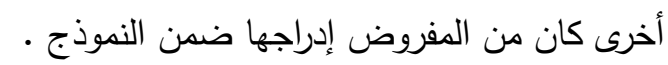

r- اختبار معنوية المتغير المستقل: باستخدام اختبار (t.test) نجد أن المتغير المستقل

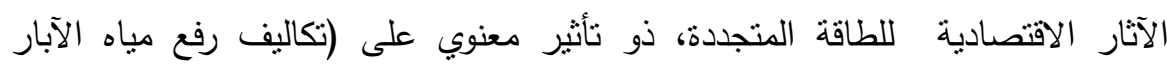

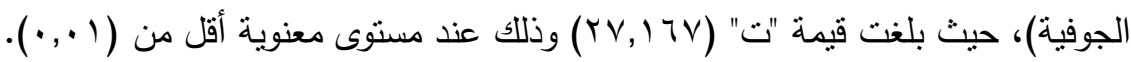
r - اختبار معنوية جودة توفيق نموذج الانحدار: لاختبار معنوية جودة نوفيق النموذج

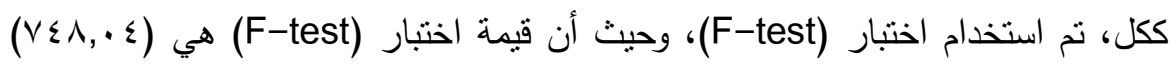

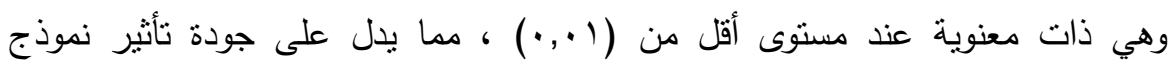
الانحدار على. واهي دات معنو

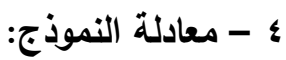

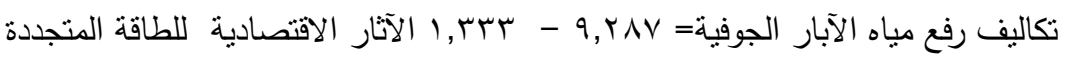
وبذلك يثبت صحة الفرض الفرعي الاول الذى ينص على: نوجد علاقة ذات دلاله

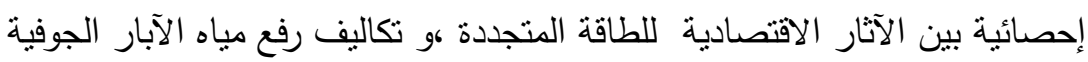


فرض فرعى ثاني: ماهي الآثار البيئية للطاقة المتجددة على تكاليف رفع مياه الابار الجوفية جدول رقم (9): نموذج الانحدار الخطي البسيط لتحديد معنوية تأثير الآثار البيئية للطاقة

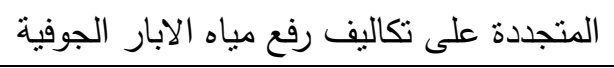

\begin{tabular}{|c|c|c|c|c|c|c|}
\hline \multirow[b]{2}{*}{ R2 } & \multicolumn{2}{|c|}{ F. test } & \multicolumn{2}{|c|}{ t. test } & \multirow{2}{*}{ المقدمات } & \multirow[b]{2}{*}{ المتغير المستقل } \\
\hline & المعنوية & القيمة & المنتوية & القيمة & & \\
\hline$\% \vee \varepsilon, r$ & $* *_{.}, \ldots$, & 107, «. & $* *, \cdot, 1$ & r), & ו ו וT, & الجزء الثابت \\
\hline & & & $* *, \cdot, 1$ & $\langle\wedge, q \leqslant)$ & $1,9 \ldots$ & الآثار البيئية للطاقة المتجدد \\
\hline
\end{tabular}

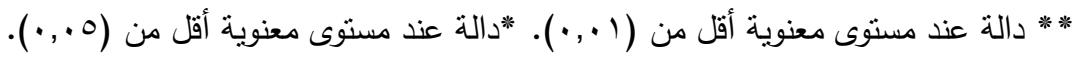

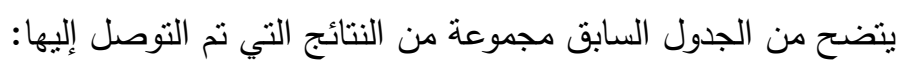

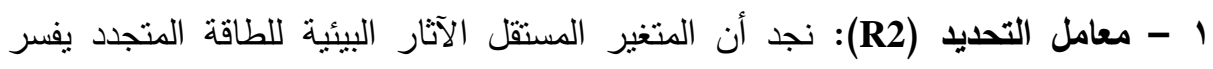

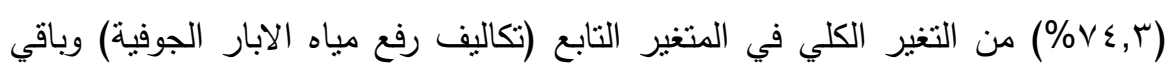

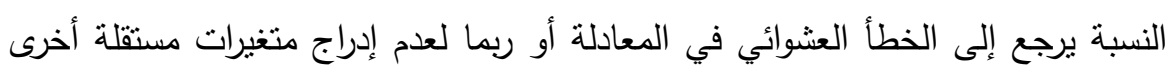

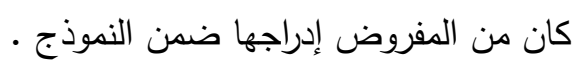

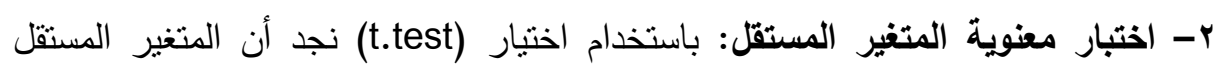
الآثار البيئية للطاقة المتجدد، ذو تأثثر معنوي على (تكاليف رفع مياه الابار الجوفية)،

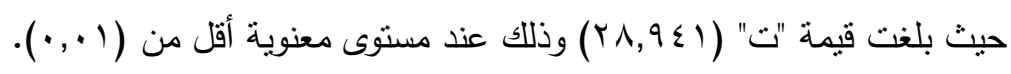

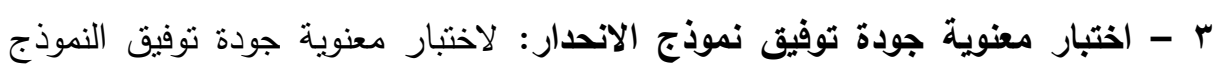

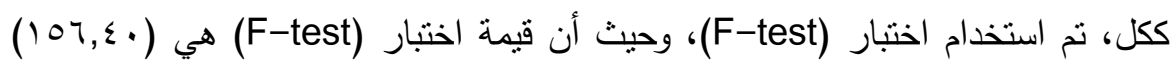
وهي ذات معنوية عند مستوى أقل من ( ( , ·)، مما يدل على جودة تأثير نموذج الانحدار

$$
\text { على تكاليف رفع مياه الابار الجوفية. }
$$

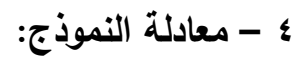

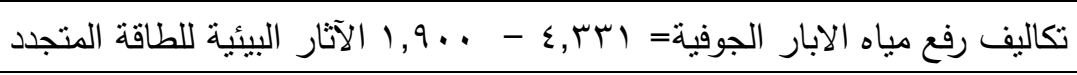
وبذلك يثبت صحة الفرض الفرعي الثاني الذى ينص على: توجد علاقة ذات دلالة إحصائية بين الآثار البيئية للطاقة المتجددة، وتكاليف رفع مياه الآبار الجوفية لئية

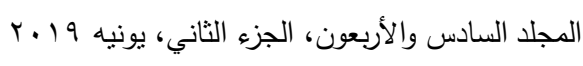


فرض فرعى ثالث: ماهي الآثار الصحية للطاقة المتجدة على تكاليف رفع مياه الابار الجوفية

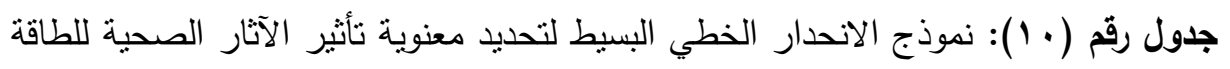

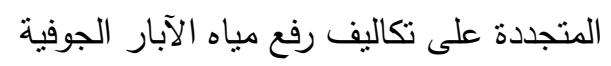

\begin{tabular}{|c|c|c|c|c|c|c|}
\hline \multirow[b]{2}{*}{$\mathbf{R} 2$} & \multicolumn{2}{|c|}{ F. test } & \multicolumn{2}{|c|}{ t. test } & \multirow{2}{*}{ المقدرة } & \multirow[b]{2}{*}{ المتغير المستقل } \\
\hline & المعنوية & القيمة & المعنوية & القيمة & & \\
\hline$\% 10,0$ & $* * ., \ldots 1$ & $17,74 \mathrm{~V}$ & $* * \cdot, \cdot 1$ & $r, 191$ & $0, Y Y \varepsilon$ & الجزء الثابت \\
\hline & & & $* *,, \cdot 1$ & $\varepsilon, \cdot A r$ & $1, \wedge 9$. & الآثار الصحية \\
\hline
\end{tabular}

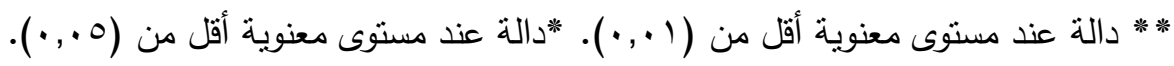

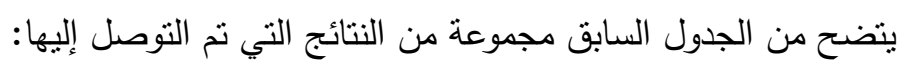
1 - معامل التحديد (R2): نجد أن المتغير المستقل الآثار الصحية للطاقة المتجددة يفسر

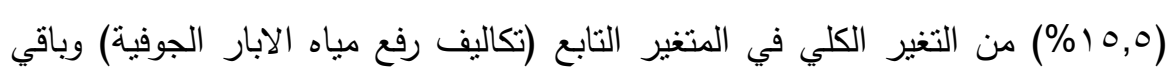

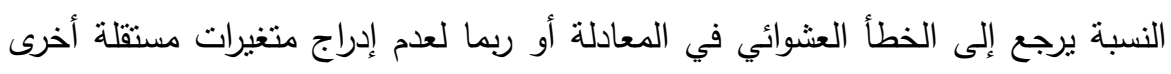

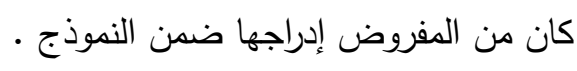
r- اختبار معنوية المتغير المستقل: باستخدام اختيار (t.test) نجد أن المتنغير المستقل

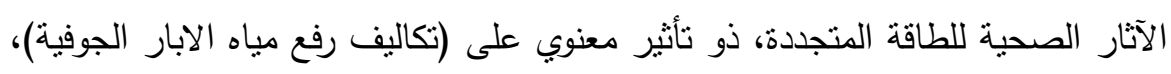

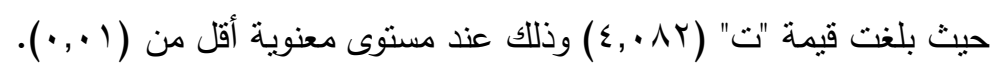

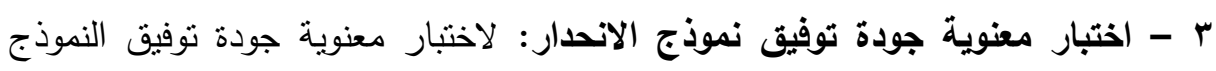

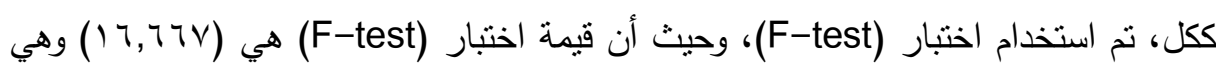

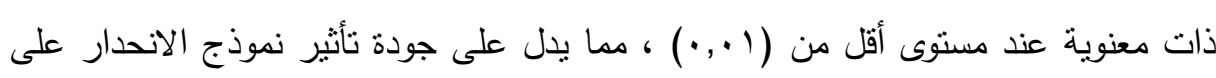

$$
\text { تكاليف رفع مياه الابار الجوفية. }
$$

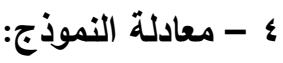

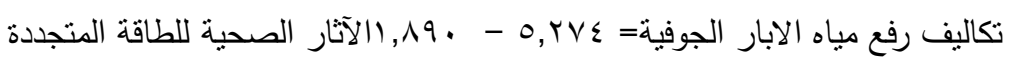

وبذلك يثبت صحة الفرض الفرعي الثالث الذى ينص على: توجد علاقة ذات دلاله

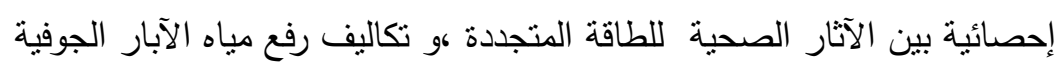


الفرض الرئيسي: توجد علاقة ذات دلاله إحصائية بين استخدام الطاقة المتجددة على تكاليف رفع مياه الآبار الجوفية جدول رقم (11): نموذج الانحدار الخطي البسيط لتحديد معنوية تأثير الآثار الصحية للطاقة المتجددة على تكاليف رفع مياه الآبار الجوفية

\begin{tabular}{|c|c|c|c|c|c|c|}
\hline \multirow[b]{2}{*}{$\mathbf{R 2}$} & \multicolumn{2}{|c|}{ F. test } & \multicolumn{2}{|c|}{ t. test } & \multirow{2}{*}{ المعرمات } & \multirow[b]{2}{*}{ المتغير المستقل } \\
\hline & المعنوية & القيمة & المعنوية & القيمة & & \\
\hline$\%$ \% , 1 & $* *, \ldots$ & $r \varepsilon, r q \varepsilon$ & $* *,, \cdot 1$ & $r, r q 0$ & $1 \leqslant, \leqslant 77$ & الجزء الثابت \\
\hline & & & ***,, 1 & $\varepsilon, q \uparrow q$ & $0, \wedge 97$ & الطاقة المتجددة \\
\hline
\end{tabular}

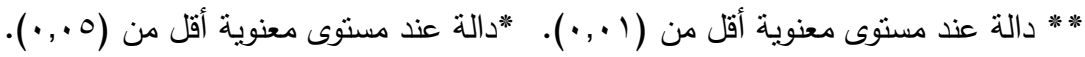
يتضح من الجدول السابق مجموعة من النتائج التي تم التوصل إليها:

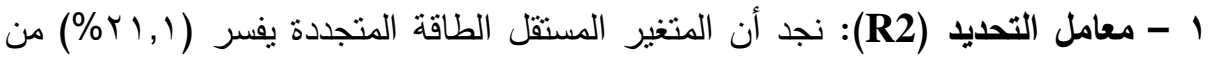

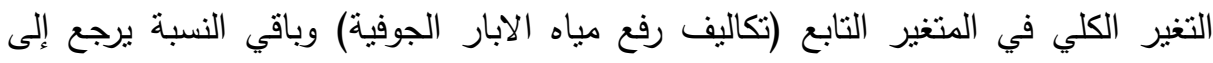

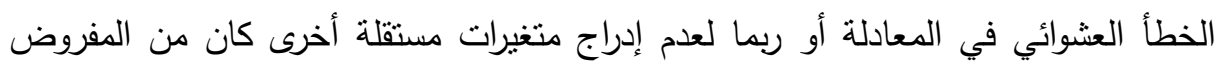

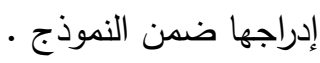
r- اختبار معنوية المتغير المستقل: باستخدام اختبار (t.test) نجد أن المتغير المستقل

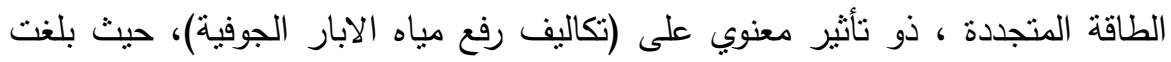

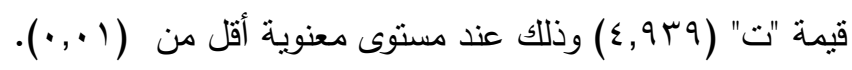

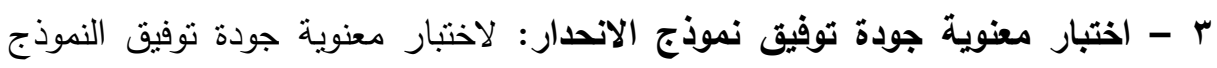

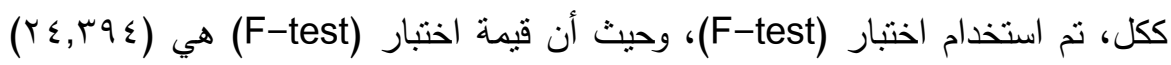
وهي ذات معنوية عند مستوى أقل من (1.,.•) ، مما يدل على جودة تأثنير نموذج الانحدار على تكاليف رفع مياه الابار الجوفية. ؛ - 2 - معادلة النموذج:

تكاليف رفع مياه الابار الجوفية = 
وبذلك يثبت صحة الفرض الرئيس الذى ينص على: توجد علاقة ذات دلاله إحصائية بين استخدام الطاقة المتجدة على تكاليف رفع مياه الآبار الجوفية

\section{تمصياهت التواسمة}

في ضوء نتائج الدراسة توصى الباحثة بالتي:

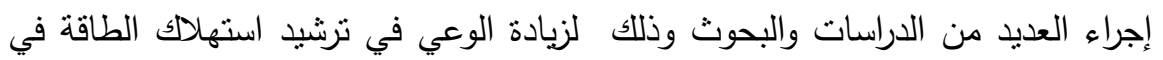

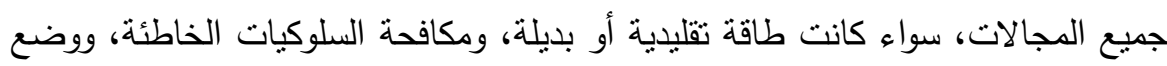
البرامج الإعلامية الهادفة إلى تعريف المواطن بأهمية الطاقات المتجددة وسبل الاستفادة منها، فضلا عن إدخال علوم الطاقات المتجددة في المناهج التعليمية لخلق جيل متعلم يعي الوضع الراهن والمستقبلي للطاقة ومشاكلها، ليبحث ويساهم في تأمين مصادر طاقة إنة بديلة ونظيفة. تتظيم العديد من الندوات والمؤتمرات وورش العمل وذلك لنطوير ودعم المؤسسات

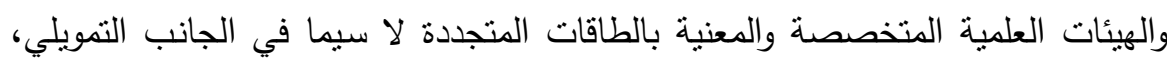
بهدف مواكبة التطور التكنولوجي الحاصل في مجال الطاقات المتجددة عالميا إنثاء وحدة متخصصة لتوفير كافة البيانات والمعلومات التي بتطلبها نطبيق استخدام الطاقة المتجدة في توليد الكهرباء في جميع المجالات وخاصة في عملية رفع مياه الآبار الجوفية.

\section{enloll}

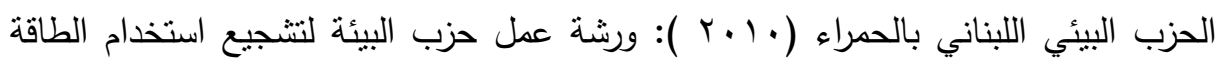
المتجددة

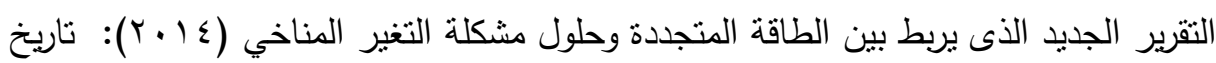

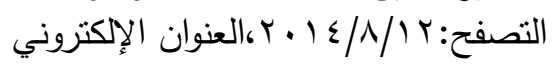

www.mmsec.com/m1-eng/windeng.htm

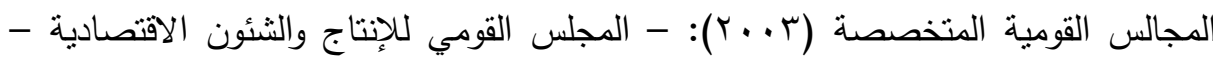

شعبة الطاقة والكهرباء والبترول - نوليد الكهرباء في مصر - مذكرة منشورة . 
الموقع الإكتروني لوكالة الطاقة الدولية الية International Energy Agency Website

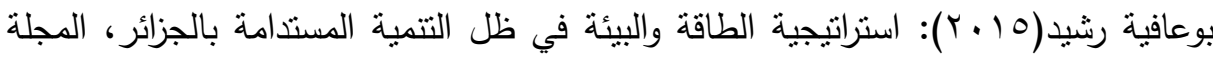

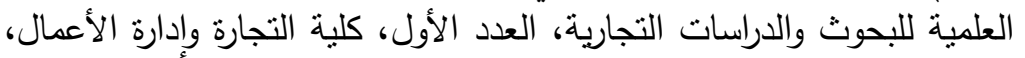
جامعة حلوان، القاهرة، مصر الاندان

حسن البنا سعد فتح: الطاقة الثمسية البديلا لواعد، مجلة فقيه للبحث والنطوير، العدد الرابع،

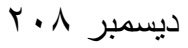

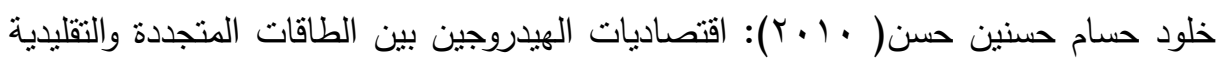

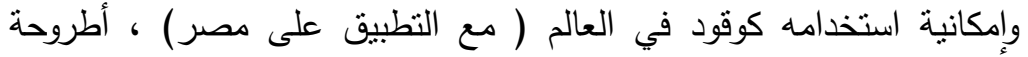
دكتوراه، كلية التجارة، جامعة عين شمس، مصرد

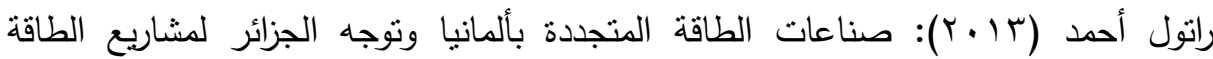

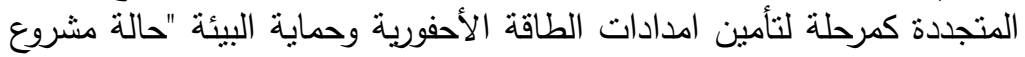

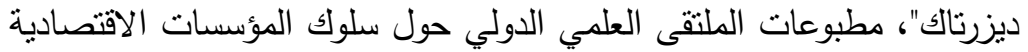

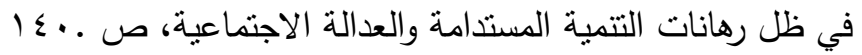

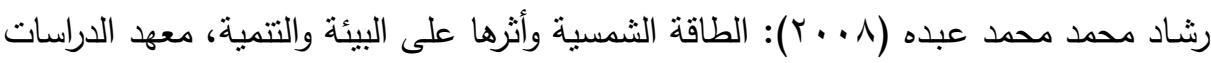

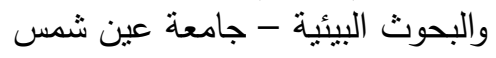

سهير محمد طلعت الغزالي(9 . . ب): التقييم الاقتصادي للآثار البيئية لتحلية المياه باستخدام الطاقة الثمسية" ، معهد الدراسات والبحوث البيئة ، جامعة عين شمس النس

عبداله عبدالقادر نصير : البيئة والتتمية المستدامة التكامل الاستراتيجي للعمل الخيري، مركز

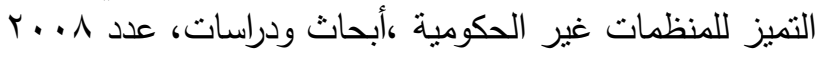

www.ngoce.org/content/nseer.doc العنوان الإكتروني عمر شريف(ع ا ـ ؟): استخدام الطاقات المتجددة ودورها في التتمية المحلية المستدامة (دراسة

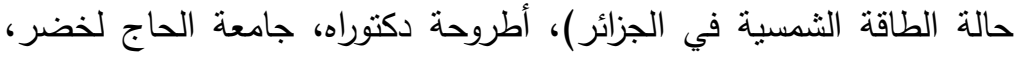
بانتة،

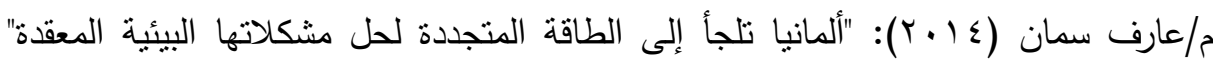
،تاريخ www.mmsec.com/m1-eng/windeng.htm الإلكتروني

محمد عبد الرازق القمحاوي(991 ()): التلوث البيئي وسبل مواجهته ، الملتقى المصري للإبداع

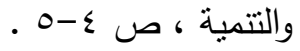




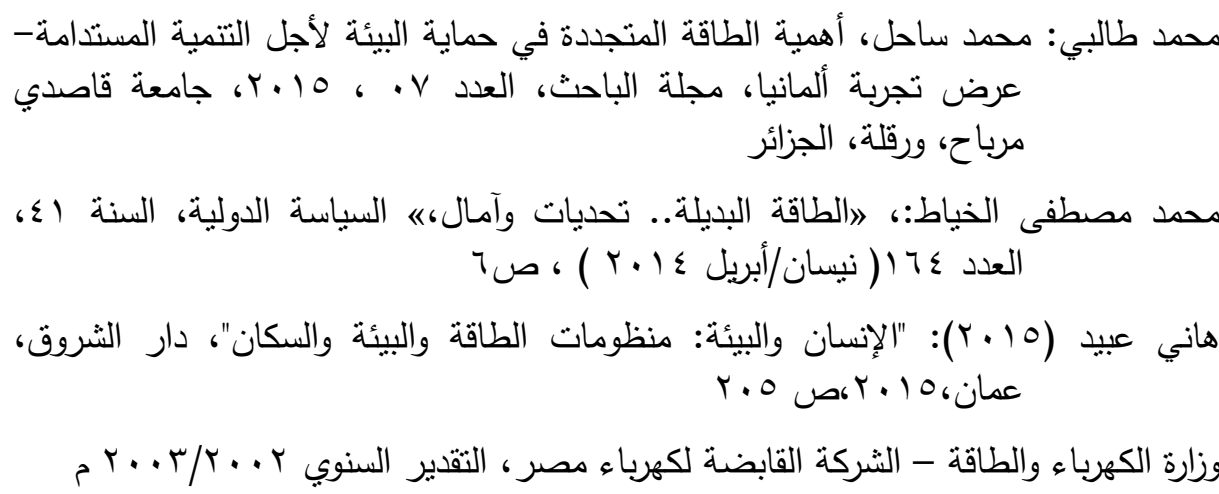

World Energy Council, World Energy Resources, London, United Kingdom (2013)

Measuring the impact of using renewable energy on the costs of raising groundwater wells For the purpose of preserving the environment "applied study

\title{
MEASURING IMPACT TO USE RENEWABLE ENERGY ON COSTS RAISING GROUNDWATER FOR A SAFETY ENVIRONMEN
} AN APPLIED STUDY

\section{Hussein M. Eissa $^{(1)}$; Moustafa A. Abou Zaid ${ }^{(2)}$ and Amira I.Labib ${ }^{(3)}$}

1) Faculty of Commerce, Ain Shams University 2) Ministry of Water Resources \& Irrigation 3) Institute of Environmental Studies \& Research, Ain Shams University

\begin{abstract}
This current study drives at measuring impact of using renewable energy on costs of elevating the underground wells' waters for the purpose of conserving the environment. Energy considers one of the 292

$$
\text { المجلد السادس والأربعون، الجزء الثاني، يونيه } 9 \text { ب. }
$$
\end{abstract}


critical challenges meeting our present world, for being one of the vitally important sectors all over the world. Energy expresses and reflects developmental processes. However, the growth and economic development the world has witnessed in the last few decades resulting in excessive consumption of natural resources, specifically, the fossil has been threatening the security of global energy warning of energy resources depletion. Another threat has been connected to energy in these few decades is the environmental pollution which has increased remarkably to affect passively the absorbing capacity of environment and creating ecological imbalance. Therefore, all the world states have been convinced with the necessity of solving and treating the environmental problems, meeting the challenge of how to produce balance between conserving the environment and achieving development at the same time. The most important study results are summed up in:

1- Renewable energy is critically important in environment's protection, for being a clean nonpolluting energy, besides expansion in its use leads to shrinkage of use of traditional energy resources which affects the environment negatively.

2- Solar energy has a promising future as a clean renewable energy that energy experts think it will be the ideal fuel for future.

The most important recommendations:

1- Increasing awareness of rationalizing energy use in all fields, either the traditional or the alternative energy, combating wrong behaviors, setting targeting media program to enlighten citizens with the value of renewable energy and its uses. Added to that, including renewable energy sciences within educational curricula to bring up a cultured generation of the present and future condition of energy problem in order to contribute secure resources of clean and renewable energy.

2- Developing and supporting specialized scientific organizations and authorities concerned with renewable energy, particularly, in funding in order to cope with recent technological advancements occur in field of global renewable energy.

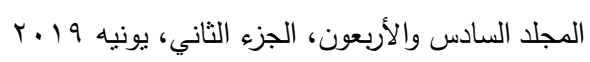

